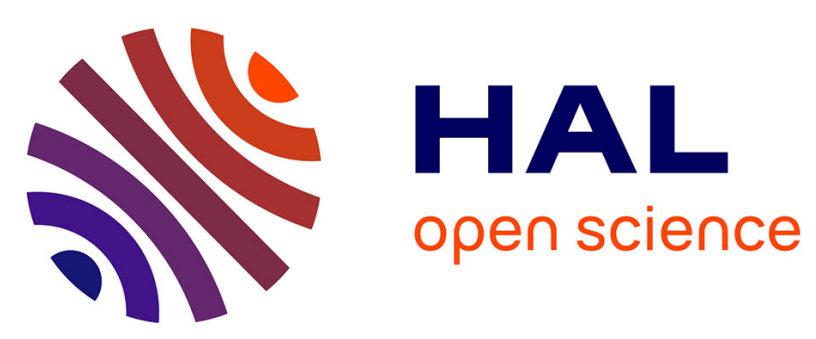

\title{
Structural Consequences of 1,4-Cyclohexanedicarboxylate Cis/trans Isomerism in Uranyl Ion Complexes: From Molecular Species to 2D and 3D Entangled Nets
}

Pierre Thuéry, Jack Harrowfield

\section{To cite this version:}

Pierre Thuéry, Jack Harrowfield. Structural Consequences of 1,4-Cyclohexanedicarboxylate Cis/trans Isomerism in Uranyl Ion Complexes: From Molecular Species to 2D and 3D Entangled Nets. Inorganic Chemistry, 2017, 56, pp.13464-13481. 10.1021/acs.inorgchem.7b02176 . cea-01618737

\section{HAL Id: cea-01618737 https://hal-cea.archives-ouvertes.fr/cea-01618737}

Submitted on 18 Oct 2017

HAL is a multi-disciplinary open access archive for the deposit and dissemination of scientific research documents, whether they are published or not. The documents may come from teaching and research institutions in France or abroad, or from public or private research centers.
L'archive ouverte pluridisciplinaire HAL, est destinée au dépôt et à la diffusion de documents scientifiques de niveau recherche, publiés ou non, émanant des établissements d'enseignement et de recherche français ou étrangers, des laboratoires publics ou privés. 


\title{
Structural Consequences of 1,4-Cyclohexanedicarboxylate cis/trans Isomerism in Uranyl Ion Complexes: from Molecular Species to 2D and 3D Entangled Nets
}

\author{
Pierre Thuéry* ${ }^{* \dagger}$ and Jack Harrowfield
}

\author{
†NIMBE, CEA, CNRS, Université Paris-Saclay, CEA Saclay, 91191 Gif-sur-Yvette, France \\ †ISIS, Université de Strasbourg, 8 allée Gaspard Monge, 67083 Strasbourg, France
}

\begin{abstract}
Cyclohexanedicarboxylic acid $\left(t-1,4-\mathrm{chdcH}_{2}\right)$ or the commercially available mixture of the cis and trans isomers $\left(c, t-1,4-\mathrm{chdcH}_{2}\right)$ have been used in the synthesis of a series of 14 uranyl ion complexes, all obtained under solvo-hydrothermal conditions, and some of them in the presence of additional metal cations and/or 2,2'-bipyridine (bipy). With its two isomeric forms having very different shapes and its great sensitivity to the experimental conditions, 1,4-chdc ${ }^{2-}$ appears to be suitable for the synthesis of uranyl ion complexes displaying a wide range of architectures. Under the conditions used, the pure trans isomer gives only the complexes [UOO ${ }_{2}(t-1,4-$ chdc) $\left.\left(\mathrm{H}_{2} \mathrm{O}\right)_{2}\right](\mathbf{1})$ and $\left[\mathrm{UO}_{2}(t-1,4-\mathrm{chdc})\right](2)$, which crystallize as one- and two-dimensional (1D and 2D) species, respectively. Complexes containing either the cis isomer alone, or mixtures of the two isomers in varying proportion, were obtained from the isomer mixture. The neutral complexes $\left[\mathrm{UO}_{2}(c-1,4-\mathrm{chdc})(\mathrm{DMF})\right](3)$ and $\left[\mathrm{UO}_{2}(c-1,4-\right.$ chdc)(bipy)] (4) are 2D and 1D assemblies, respectively, while all the other complexes are anionic and include various counterions. $\left[\mathrm{C}\left(\mathrm{NH}_{2}\right)_{3}\right]_{3}\left[\mathrm{H}_{2} \mathrm{NMe}_{2}\right]\left[\left(\mathrm{UO}_{2}\right)_{4}(c-1,4-\mathrm{chdc})_{6}\right] \cdot \mathrm{H}_{2} \mathrm{O}(5)$ crystallizes as a three-dimensional (3D) framework with $\left\{10^{3}\right\}$ topology. While $\left[\mathrm{H}_{2} \mathrm{NMe}_{2}\right]_{2}\left[\left(\mathrm{UO}_{2}\right)_{2}(c-1,4-\mathrm{chdc})_{2}(t-1,4-\mathrm{chdc})\right] \cdot \mathrm{DMF} \cdot 2 \mathrm{H}_{2} \mathrm{O}(6)$ is a $1 \mathrm{D}$ ladder-like polymer, $\left[\mathrm{H}_{2} \mathrm{NMe}_{2}\right]_{2}\left[\left(\mathrm{UO}_{2}\right)_{2}(c-1,4-\mathrm{chdc})(t-1,4-\mathrm{chdc})_{2}\right] \cdot 2 \mathrm{H}_{2} \mathrm{O}(7)$, which differs in the cis/trans ratio, is a threefold $2 \mathrm{D}$ interpenetrated network with $\left\{6^{3}\right\}$ honeycomb topology. The related $\left[\mathrm{H}_{2} \mathrm{NMe}_{2}\right]_{2}\left[\left(\mathrm{UO}_{2}\right)_{2}(c, t-1,4-\mathrm{chdc})_{3}\right] \cdot 2.5 \mathrm{H}_{2} \mathrm{O}(\mathbf{8})$, with one disordered ligand of uncertain geometry, is a threefold 3D interpenetrated system. The two isomorphous complexes $\left[\mathrm{Co}(\text { bipy })_{3}\right]\left[\left(\mathrm{UO}_{2}\right)_{2}(c-1,4-\mathrm{chdc})_{3}\right] \cdot 1.5 \mathrm{H}_{2} \mathrm{O}(\mathbf{9})$ and $\left[\mathrm{Cd}(\text { bipy })_{3}\right]\left[\left(\mathrm{UO}_{2}\right)_{2}(c-1,4-\mathrm{chdc})_{3}\right] \cdot 1.5 \mathrm{H}_{2} \mathrm{O}(\mathbf{1 0})$ form $3 \mathrm{D}$ frameworks with the $\left\{10^{3}\right\}$ srs topological type. In contrast, $\left[\mathrm{Ni}(\text { bipy })_{3}\right]_{2}\left[\left(\mathrm{UO}_{2}\right)_{4}(c-1,4-\mathrm{chdc})_{2}(t-1,4-\right.$ chdc) $\left.\left(\mathrm{NO}_{3}\right)_{6}\right] \cdot 2 \mathrm{H}_{2} \mathrm{O}(\mathbf{1 1})$ is a molecular, tetranuclear complex due to the presence of terminal nitrate ligands. Twofold $3 \mathrm{D}$ interpenetration of frameworks with $\left\{10^{3}\right\}$ ths topology is observed in $\left[\mathrm{Cu}(\text { bipy })_{2}\right]_{2}\left[\left(\mathrm{UO}_{2}\right)_{2}(c-1,4-\mathrm{chdc})_{2}(t-1,4-\right.$ chdc) $] \cdot 2 \mathrm{H}_{2} \mathrm{O}(\mathbf{1 2})$, while $\left[\mathrm{Zn}(\text { bipy })_{3}\right]\left[\left(\mathrm{UO}_{2}\right)_{2}(c-1,4-\mathrm{chdc})_{3}\right] \cdot 4 \mathrm{H}_{2} \mathrm{O}(\mathbf{1 3})$ crystallizes as a $2 \mathrm{D}$ net with the common $\left\{4.8^{2}\right\}$ fes topological type. The additional $\mathrm{Pb}^{\Pi \mathrm{I}}$ cation is an essential part of the $3 \mathrm{D}$ framework formed in $\left[\mathrm{UO}_{2} \mathrm{~Pb}_{2}(c-1,4-\right.$ chdc) $\left.(t-1,4-c h d c)_{2}(\text { bipy })_{2}\right](14)$, in which uranyl and its ligands alone form 1D subunits. Together with previous results, the solid state uranyl emission properties of seven of the present complexes evidence a general trend, with the maxima for the complexes with $\mathrm{O}_{6}$ equatorial environments being blue-shifted with respect to those for $\mathrm{O}_{5}$ environments.
\end{abstract}




\section{INTRODUCTION}

Although an impressive range of polycarboxylic acids have been used in the design of uranylorganic complexes and coordination polymers, as is evident from reviews recently devoted to this topic, ${ }^{1-3}$ some simple and easily accessible families had, until quite recently, been virtually neglected, a case in point being that of the cyclohexanedicarboxylic acids. A particular feature of these acids is that, in addition to their availability as 1,2-, 1,3- and 1,4-positional isomers like their aromatic benzenedicarboxylic acid counterparts, they display the added levels of cis/trans isomerism and also chirality in some members of the family, as well as the possibility of axial or equatorial positioning of the carboxylic groups. What is lost in rigidity and associated possible predictability of the geometry of the complexes formed is gained in variety and versatility, as is particularly apparent when experimental conditions are varied, notably through the use of additional metal cations to generate heterometallic species. We recently undertook an investigation of these complexes, beginning with trans-1,2-cyclohexanedicarboxylate, either in its racemic or $(1 R, 2 R)$ enantiopure form. This resulted in the isolation of several homo- and heterometallic complexes and coordination polymers, including a group of tetrahedral and cuboidal clusters obtained with alkali, alkaline-earth, silver(I) or lead(II) additional cations. ${ }^{4,5}$ Although our studies of complexes of cis-1,2-cyclohexanedicarboxylate have to date been limited, they do indicate significant differences to be associated with this isomeric form, providing reason for an extension to examination of the complexes of cis- and trans-1,4-cyclohexanedicarboxylic acid, for which but a single uranyl molecular complex of the trans isomer is known. ${ }^{6}$ This acid is the alicyclic counterpart of terephthalic acid, which has been used in the synthesis of several coordination polymers, ${ }^{7-19}$ most often one- or two-dimensional (1D or $2 \mathrm{D}$ ), with only two cases of threedimensional (3D) frameworks, ${ }^{12,16}$ and also some examples of interpenetrated nets. ${ }^{8,14,19}$ Some of 
these complexes are heterometallic, ${ }^{7,11,13,18}$ and display photocatalytic activity. ${ }^{7,13,18}$ We used two commercially available forms of 1,4-cyclohexanedicarboxylic acid, the pure trans form $(t-1,4-$ $\mathrm{chdcH}_{2}$ ), which, when the two acid groups are in equatorial position, is geometrically close to terephthalic acid, and a mixture of $c i$ and trans isomers $\left(c, t-1,4-\mathrm{chdcH}_{2}\right)$. Through variation of the organic cosolvent in solvo-hydrothermal processes, and addition of transition metal or lead(II) cations associated with 2,2'-bipyridine (bipy), 14 complexes were obtained and have been characterized by their crystal structure and, for 10 of them, their emission spectrum in the solid state. This series displays the whole range of dimensionalities, from molecular (0D) to 3D, and provides also three novel examples of interpenetrated nets, as could be expected with ditopic ligands in which the divergent donor groups are widely separated. Although they are not extremely common, the list of entangled nets ${ }^{20-25}$ in uranyl coordination chemistry is steadily growing and covers a very diverse set of topologies..$^{8,14,19,26-40}$

\section{EXPERIMENTAL SECTION}

Syntheses. Caution! Uranium is a radioactive and chemically toxic element, and uraniumcontaining samples must be handled with suitable care and protection.

$\mathrm{UO}_{2}\left(\mathrm{NO}_{3}\right)_{2} \cdot 6 \mathrm{H}_{2} \mathrm{O}$ (depleted uranium, R. P. Normapur, 99\%), $\mathrm{Co}\left(\mathrm{NO}_{3}\right)_{2} \cdot 6 \mathrm{H}_{2} \mathrm{O}$, $\mathrm{Ni}\left(\mathrm{NO}_{3}\right)_{2} \cdot 6 \mathrm{H}_{2} \mathrm{O}$ and $\mathrm{Pb}\left(\mathrm{NO}_{3}\right)_{2}$ were purchased from Prolabo, trans-1,4-cyclohexanedicarboxylic acid $\left(t-1,4-\mathrm{chdcH}_{2}\right)$ was from Alfa-Aesar, 1,4-cyclohexanedicarboxylic acid (mixture of cis and trans isomers, $\left.c, t-1,4-\mathrm{chdcH}_{2}\right), \mathrm{Cu}\left(\mathrm{NO}_{3}\right)_{2} \cdot 2.5 \mathrm{H}_{2} \mathrm{O}$ and $\mathrm{Zn}\left(\mathrm{NO}_{3}\right)_{2} \cdot 6 \mathrm{H}_{2} \mathrm{O}$ were from Aldrich, and $\mathrm{Cd}\left(\mathrm{NO}_{3}\right)_{2} \cdot 4 \mathrm{H}_{2} \mathrm{O}$ and 2,2'-bipyridine (bipy) were from Fluka. Elemental analyses were performed by MEDAC Ltd. at Chobham, UK. For all syntheses, the mixtures in demineralized water plus various organic solvents, either $N, N$-dimethylformamide (DMF), tetrahydrofuran (THF), 
acetonitrile, or methanol, were placed in $10 \mathrm{~mL}$ tightly closed glass vessels and heated at $150{ }^{\circ} \mathrm{C}$ under autogenous pressure.

$\left[\mathrm{UO}_{2}(t-1,4-c h d c)\left(\mathrm{H}_{2} \mathrm{O}\right)_{2}\right](\mathbf{1}) \cdot t-1,4-\mathrm{chdcH} \mathrm{H}_{2}(17 \mathrm{mg}, 0.10 \mathrm{mmol})$ and $\mathrm{UO}_{2}\left(\mathrm{NO}_{3}\right)_{2} \cdot 6 \mathrm{H}_{2} \mathrm{O}(50$ $\mathrm{mg}, 0.10 \mathrm{mmol})$ were dissolved in THF $(0.3 \mathrm{~mL})$ and water $(0.7 \mathrm{~mL})$. Yellow crystals of complex 1 were obtained within one week (23 mg, $48 \%$ yield). Anal. Calcd for $\mathrm{C}_{8} \mathrm{H}_{14} \mathrm{O}_{8} \mathrm{U}: \mathrm{C}, 20.18 ; \mathrm{H}$, 2.96. Found: C, 20.30; H, 2.84\%.

$\left[U O_{2}(t-1,4-c h d c)\right](2) . t-1,4-c_{d c H}(17 \mathrm{mg}, 0.10 \mathrm{mmol}), \mathrm{UO}_{2}\left(\mathrm{NO}_{3}\right)_{2} \cdot 6 \mathrm{H}_{2} \mathrm{O}(50 \mathrm{mg}, 0.10$ mmol), and guanidinium nitrate $(24 \mathrm{mg}, 0.20 \mathrm{mmol})$ were dissolved in $\mathrm{CH}_{3} \mathrm{CN}(0.2 \mathrm{~mL})$ and water (0.6 mL). Yellow crystals of complex 2 were obtained overnight $(11 \mathrm{mg}, 25 \%$ yield). Anal. Calcd for $\mathrm{C}_{8} \mathrm{H}_{10} \mathrm{O}_{6} \mathrm{U}: \mathrm{C}, 21.83 ; \mathrm{H}, 2.29$. Found: C, 21.94; H, $2.23 \%$.

$\left[\mathrm{UO}_{2}(c-1,4-c h d c)(D M F)\right](3) . c, t-1,4-\mathrm{chdcH}_{2}(17 \mathrm{mg}, 0.10 \mathrm{mmol}), \mathrm{UO}_{2}\left(\mathrm{NO}_{3}\right)_{2} \cdot 6 \mathrm{H}_{2} \mathrm{O}(50$ $\mathrm{mg}, 0.10 \mathrm{mmol})$, and $\mathrm{Cd}\left(\mathrm{NO}_{3}\right)_{2} \cdot 4 \mathrm{H}_{2} \mathrm{O}(31 \mathrm{mg}, 0.10 \mathrm{mmol})$ were dissolved in $\mathrm{DMF}(0.2 \mathrm{~mL})$ and water $(0.6 \mathrm{~mL})$. Yellow crystals of complex 3 were obtained in low yield overnight. Longer heating periods consistently gave complex $\mathbf{8}$, so that complex $\mathbf{3}$ could not be isolated in quantities enabling elemental analysis.

$\left[\mathrm{UO}_{2}(c-1,4-c h d c)\left(\right.\right.$ bipy)] (4). c,t-1,4-chdcH $\mathrm{H}_{2}(17 \mathrm{mg}, 0.10 \mathrm{mmol}), \mathrm{UO}_{2}\left(\mathrm{NO}_{3}\right)_{2} \cdot 6 \mathrm{H}_{2} \mathrm{O}(50$ $\mathrm{mg}, 0.10 \mathrm{mmol})$, and 2,2'-bipyridine $(16 \mathrm{mg}, 0.10 \mathrm{mmol})$ were dissolved in DMF $(0.2 \mathrm{~mL})$ and water $(0.7 \mathrm{~mL})$. Yellow crystals of complex 4 were obtained in low yield overnight. The yield was not improved upon prolonged heating.

$\left[\mathrm{C}\left(\mathrm{NH}_{2}\right)_{3}\right]_{3}\left[\mathrm{H}_{2} \mathrm{NMe}_{2}\right]\left[\left(\mathrm{UO}_{2}\right)_{4}(\mathrm{c}-1,4-\mathrm{chdc})_{6}\right] \cdot \mathrm{H}_{2} \mathrm{O}(5) . c, t-1,4-\mathrm{chdcH} \mathrm{H}_{2}(17 \mathrm{mg}, 0.10 \mathrm{mmol})$, $\mathrm{UO}_{2}\left(\mathrm{NO}_{3}\right)_{2} \cdot 6 \mathrm{H}_{2} \mathrm{O}(50 \mathrm{mg}, 0.10 \mathrm{mmol})$, and guanidinium nitrate $(24 \mathrm{mg}, 0.20 \mathrm{mmol})$ were dissolved in DMF $(0.2 \mathrm{~mL})$ and water $(0.7 \mathrm{~mL})$. Yellow crystals of complex 5 were obtained within three 
days (19 mg, 49\% yield based on the acid). Anal. Calcd for $\mathrm{C}_{53} \mathrm{H}_{88} \mathrm{~N}_{10} \mathrm{O}_{33} \mathrm{U}_{4}: \mathrm{C}, 27.14 ; \mathrm{H}, 3.78 ; \mathrm{N}$, 5.97. Found: C, 27.28; H, 3.62; N, 5.85\%.

$\left[\mathrm{H}_{2} \mathrm{NMe}_{2}\right]_{2}\left[\left(\mathrm{UO}_{2}\right)_{2}(c-1,4-\mathrm{chdc})_{2}(t-1,4-\mathrm{chdc})\right] \cdot \mathrm{DMF} \cdot 2 \mathrm{H}_{2} \mathrm{O}$ (6). c,t-1,4-chdcH $\mathrm{H}_{2}(17 \mathrm{mg}, 0.10$ $\mathrm{mmol}), \mathrm{UO}_{2}\left(\mathrm{NO}_{3}\right)_{2} \cdot 6 \mathrm{H}_{2} \mathrm{O}(35 \mathrm{mg}, 0.07 \mathrm{mmol})$, and $\mathrm{Mn}\left(\mathrm{NO}_{3}\right)_{2} \cdot 4 \mathrm{H}_{2} \mathrm{O}(25 \mathrm{mg}, 0.10 \mathrm{mmol})$ were dissolved in DMF $(0.2 \mathrm{~mL})$ and water $(0.6 \mathrm{~mL})$. Yellow crystals of complex 6 were obtained in low yield overnight. Longer heating periods consistently gave complex $\mathbf{8}$, so that complex $\mathbf{6}$ could not be isolated in a yield enabling elemental analysis.

$\left[\mathrm{H}_{2} \mathrm{NMe}_{2}\right]_{2}\left[\left(\mathrm{UO}_{2}\right)_{2}(c-1,4-c h d c)(t-1,4-c h d c)_{2}\right] \cdot 2 \mathrm{H}_{2} \mathrm{O} \quad$ (7). $\quad c, t-1,4-\mathrm{chdcH}_{2} \quad(17 \mathrm{mg}, \quad 0.10$ mmol), $\mathrm{UO}_{2}\left(\mathrm{NO}_{3}\right)_{2} \cdot 6 \mathrm{H}_{2} \mathrm{O}(35 \mathrm{mg}, 0.07 \mathrm{mmol})$, and $\mathrm{Pb}\left(\mathrm{NO}_{3}\right)_{2}(33 \mathrm{mg}, 0.10 \mathrm{mmol})$ were dissolved in DMF $(0.2 \mathrm{~mL})$, and water $(0.7 \mathrm{~mL})$. Yellow crystals of complex 7 were obtained in low yield overnight. Longer heating periods consistently gave complex $\mathbf{8}$, so that complex $\mathbf{7}$ could not be isolated in a yield enabling elemental analysis.

$\left[\mathrm{H}_{2} \mathrm{NMe}_{2}\right]_{2}\left[\left(\mathrm{UO}_{2}\right)_{2}(c, t-1,4-c h d c)_{3}\right] \cdot 2.5 \mathrm{H}_{2} \mathrm{O}(8) . c, t-1,4-\mathrm{chdcH}_{2}(17 \mathrm{mg}, 0.10 \mathrm{mmol})$ and $\mathrm{UO}_{2}\left(\mathrm{NO}_{3}\right)_{2} \cdot 6 \mathrm{H}_{2} \mathrm{O}(50 \mathrm{mg}, 0.10 \mathrm{mmol})$ were dissolved in DMF $(0.2 \mathrm{~mL})$ and water $(0.7 \mathrm{~mL})$. Yellow crystals of complex 8 were obtained within one week (5 mg, 13\% yield based on the acid). Anal. Calcd for $\mathrm{C}_{28} \mathrm{H}_{51} \mathrm{~N}_{2} \mathrm{O}_{18.5} \mathrm{U}_{2}$ : C, 28.31; H, 4.33; N, 2.36. Found: C, 28.37; H, 3.89; N, 2.69\%. Complex 8 was also obtained in similar experiments with additional $\mathrm{Mn}^{\mathrm{II}}, \mathrm{Cu}^{\mathrm{II}}, \mathrm{Cd}^{\mathrm{II}}$ or $\mathrm{Pb}^{\mathrm{II}}$ nitrate, or $\left[\mathrm{Co}(\mathrm{en})_{3}\right] \mathrm{Cl}_{3} \cdot 3 \mathrm{H}_{2} \mathrm{O}$ (en = ethylenediamine).

$\left[\mathrm{Co}(\text { bipy })_{3}\right]\left[\left(\mathrm{UO}_{2}\right)_{2}(c-1,4-c h d c)_{3}\right] \cdot 1.5 \mathrm{H}_{2} \mathrm{O} \quad$ (9). $\quad c, t-1,4-\mathrm{chdcH}_{2} \quad(17 \mathrm{mg}, 0.10 \mathrm{mmol})$, $\mathrm{UO}_{2}\left(\mathrm{NO}_{3}\right)_{2} \cdot 6 \mathrm{H}_{2} \mathrm{O}(35 \mathrm{mg}, 0.07 \mathrm{mmol}), \mathrm{Co}\left(\mathrm{NO}_{3}\right)_{2} \cdot 6 \mathrm{H}_{2} \mathrm{O}(15 \mathrm{mg}, 0.05 \mathrm{mmol})$, and 2,2'-bipyridine (24 mg, $0.15 \mathrm{mmol})$ were dissolved in DMF $(0.2 \mathrm{~mL})$ and water $(0.6 \mathrm{~mL})$. Orange crystals of complex 9 were obtained within three days $(38 \mathrm{mg}, 71 \%$ yield). Anal. Calcd for $\mathrm{C}_{54} \mathrm{H}_{57} \mathrm{CoN}_{6} \mathrm{O}_{17.5} \mathrm{U}_{2}: \mathrm{C}, 40.41 ; \mathrm{H}, 3.58 ; \mathrm{N}$, 5.24. Found: $\mathrm{C}, 40.32 ; \mathrm{H}, 3.45 ; \mathrm{N}, 5.15 \%$. 
$\left[C d(\text { bipy })_{3}\right]\left[\left(\mathrm{UO}_{2}\right)_{2}(c-1,4-c h d c)_{3}\right] \cdot 1.5 \mathrm{H}_{2} \mathrm{O} \quad(\mathbf{1 0}) . \quad c, t-1,4-\mathrm{chdcH}_{2} \quad(17 \mathrm{mg}, 0.10 \mathrm{mmol})$, $\mathrm{UO}_{2}\left(\mathrm{NO}_{3}\right)_{2} \cdot 6 \mathrm{H}_{2} \mathrm{O}(35 \mathrm{mg}, 0.07 \mathrm{mmol}), \mathrm{Cd}\left(\mathrm{NO}_{3}\right)_{2} \cdot 4 \mathrm{H}_{2} \mathrm{O}(16 \mathrm{mg}, 0.05 \mathrm{mmol})$, and 2,2'-bipyridine (24 mg, $0.15 \mathrm{mmol})$ were dissolved in DMF $(0.2 \mathrm{~mL})$ and water $(0.6 \mathrm{~mL})$. Yellow crystals of complex 10 were obtained within three days (32 mg, 58\% yield). Anal. Calcd for $\mathrm{C}_{54} \mathrm{H}_{57} \mathrm{CdN}_{6} \mathrm{O}_{17.5} \mathrm{U}_{2}: \mathrm{C}, 39.11 ; \mathrm{H}, 3.46 ; \mathrm{N}, 5.07$. Found: C, 38.92; H, 3.28; N, 4.89\%.

$\left[\mathrm{Ni}(\text { bipy })_{3}\right]_{2}\left[\left(\mathrm{UO}_{2}\right)_{4}(\mathrm{c}-1,4-\mathrm{chdc})_{2}(t-1,4-\mathrm{chdc})\left(\mathrm{NO}_{3}\right)_{6}\right] \cdot 2 \mathrm{H}_{2} \mathrm{O}$ (11). c,t-1,4-chdcH ${ }_{2}(17 \mathrm{mg}$, $0.10 \mathrm{mmol}), \mathrm{UO}_{2}\left(\mathrm{NO}_{3}\right)_{2} \cdot 6 \mathrm{H}_{2} \mathrm{O}(50 \mathrm{mg}, 0.10 \mathrm{mmol}), \mathrm{Ni}\left(\mathrm{NO}_{3}\right)_{2} \cdot 6 \mathrm{H}_{2} \mathrm{O}(15 \mathrm{mg}, 0.05 \mathrm{mmol})$, and 2,2'bipyridine (24 mg, $0.15 \mathrm{mmol})$ were dissolved in methanol $(0.2 \mathrm{~mL})$ and water $(0.6 \mathrm{~mL})$. Pink crystals of complex 11 were obtained within three days (18 mg, 24\% yield based on U). Anal. Calcd for $\mathrm{C}_{84} \mathrm{H}_{82} \mathrm{~N}_{18} \mathrm{Ni}_{2} \mathrm{O}_{40} \mathrm{U}_{4}:$ C, 33.04; H, 2.71; N, 8.26. Found: C, 33.27; H, 2.57; N, 8.15\%.

$\left[\mathrm{Cu}(\text { bipy })_{2}\right]_{2}\left[\left(\mathrm{UO}_{2}\right)_{2}(c-1,4-c h d c)_{2}(t-1,4-c h d c)\right] \cdot 2 \mathrm{H}_{2} \mathrm{O}$ (12). c,t-1,4-chdcH $\mathrm{H}_{2} \quad(17 \mathrm{mg}, 0.10$ $\mathrm{mmol}), \mathrm{UO}_{2}\left(\mathrm{NO}_{3}\right)_{2} \cdot 6 \mathrm{H}_{2} \mathrm{O}(35 \mathrm{mg}, 0.07 \mathrm{mmol}), \mathrm{Cu}\left(\mathrm{NO}_{3}\right)_{2} \cdot 2.5 \mathrm{H}_{2} \mathrm{O}(12 \mathrm{mg}, 0.05 \mathrm{mmol})$, and 2,2'bipyridine (16 mg, $0.10 \mathrm{mmol})$ were dissolved in DMF $(0.2 \mathrm{~mL})$ and water $(0.6 \mathrm{~mL})$. Deep orange crystals of complex 12 were obtained within one week ( $24 \mathrm{mg}, 52 \%$ yield based on $\mathrm{Cu}$ ). Anal. Calcd for $\mathrm{C}_{64} \mathrm{H}_{66} \mathrm{Cu}_{2} \mathrm{~N}_{8} \mathrm{O}_{18} \mathrm{U}_{2}: \mathrm{C}, 41.81 ; \mathrm{H}, 3.62 ; \mathrm{N}, 6.10$. Found: $\mathrm{C}, 41.76 ; \mathrm{H}, 3.31 ; \mathrm{N}, 6.10 \%$.

$\left[\mathrm{Zn}(\text { bipy })_{3}\right]\left[\left(\mathrm{UO}_{2}\right)_{2}(c-1,4-c h d c)_{3}\right] \cdot 4 \mathrm{H}_{2} \mathrm{O} \quad$ (13). $\quad c, t-1,4-\mathrm{chdcH}_{2} \quad(17 \mathrm{mg}, \quad 0.10 \mathrm{mmol})$, $\mathrm{UO}_{2}\left(\mathrm{NO}_{3}\right)_{2} \cdot 6 \mathrm{H}_{2} \mathrm{O}(35 \mathrm{mg}, 0.07 \mathrm{mmol}), \mathrm{Zn}\left(\mathrm{NO}_{3}\right)_{2} \cdot 6 \mathrm{H}_{2} \mathrm{O}(15 \mathrm{mg}, 0.05 \mathrm{mmol})$, and 2,2'-bipyridine (24 mg, $0.15 \mathrm{mmol})$ were dissolved in DMF $(0.2 \mathrm{~mL})$ and water $(0.6 \mathrm{~mL})$. Yellow crystals of complex 13 were obtained within three days (18 mg, 33\% yield). Anal. Calcd for $\mathrm{C}_{54} \mathrm{H}_{62} \mathrm{~N}_{6} \mathrm{O}_{20} \mathrm{U}_{2} \mathrm{Zn}: \mathrm{C}, 39.15 ; \mathrm{H}, 3.77 ; \mathrm{N}, 5.07$. Found: C, 39.02; H, 3.18; N, 4.94\%.

$\left[\mathrm{UO}_{2} \mathrm{~Pb}_{2}(c-1,4-c h d c)(t-1,4-c h d c)_{2}(\text { bipy })_{2}\right] \quad$ (14). $c, t-1,4-\mathrm{chdcH}_{2} \quad(17 \mathrm{mg}, 0.10 \mathrm{mmol})$, $\mathrm{UO}_{2}\left(\mathrm{NO}_{3}\right)_{2} \cdot 6 \mathrm{H}_{2} \mathrm{O}(50 \mathrm{mg}, 0.10 \mathrm{mmol}), \mathrm{Pb}\left(\mathrm{NO}_{3}\right)_{2}(33 \mathrm{mg}, 0.10 \mathrm{mmol})$, and 2,2'-bipyridine (24 mg, $0.15 \mathrm{mmol})$ were dissolved in DMF $(0.2 \mathrm{~mL})$ and water $(0.6 \mathrm{~mL})$. Yellow crystals of complex 14 
were obtained within three days. ( $7 \mathrm{mg}, 14 \%$ yield based on the acid). Anal. Calcd for $\mathrm{C}_{44} \mathrm{H}_{46} \mathrm{~N}_{4} \mathrm{O}_{14} \mathrm{~Pb}_{2} \mathrm{U}$ : C, 35.06; H, 3.08; N, 3.72. Found: C, 34.92; H, 2.89; N, 3.67\%.

Crystallography. The data were collected at 150(2) K on a Nonius Kappa-CCD area detector diffractometer ${ }^{41}$ (Mo K $\alpha$ radiation, $\lambda=0.71073 \AA$ ). The data (combinations of $\varphi$ - and $\omega$ scans with a minimum redundancy of at least 4 for $90 \%$ of the reflections) were processed with HKL2000 ${ }^{42}$ Absorption effects were corrected empirically with the program SCALEPACK. ${ }^{42}$ The structures were solved by intrinsic phasing with SHELXT, ${ }^{43}$ and refined by full-matrix leastsquares on $F^{2}$ with SHELXL-2014. ${ }^{44}$ Two-component twinning in complexes 7, 8 and $\mathbf{1 2}$ was detected with TwinRotMat (implemented in PLATON ${ }^{45}$ ) and taken into account in the refinement. All non-hydrogen atoms were refined with anisotropic displacement parameters. Restraints on bond lengths, angles and/or displacement parameters were applied in the disordered parts and/or solvent molecules in complexes 5-8 and 10. Some water solvent molecules in 7-10 were given occupancy parameters of 0.5 so as to account for disorder over two sites or to retain acceptable displacement parameters. The hydrogen atoms bound to oxygen and nitrogen atoms were retrieved from difference Fourier maps when possible, and the carbon-bound hydrogen atoms (as well as those bound to nitrogen in the dimethylammonium cations in $\mathbf{5 , 7}$ and $\mathbf{8}$ ) were introduced at calculated positions; all hydrogen atoms were treated as riding atoms with an isotropic displacement parameter equal to 1.2 times that of the parent atom (1.5 for $\mathrm{CH}_{3}$, with optimized geometry). The dimethylammonium cation in $\mathbf{5}$ is disordered around the threefold rotation axis, while both cations are badly resolved in $\mathbf{8}$, one being disordered around an inversion centre and the other having been given an occupancy parameter of 0.5 for charge balance and in order to retain acceptable displacement parameters. In complexes $\mathbf{6}$ and $\mathbf{8}$, two carbon atoms in a dicarboxylate ligand are disordered over two positions, further disorder (of the carboxylate groups in particular) 
in $\mathbf{6}$ being unresolved. Some voids in the lattice of $\mathbf{1 3}$ indicate the presence of other, unresolved water solvent molecules, and the corresponding electron density was taken into account with the SQUEEZE software ${ }^{45}$ Crystal data and structure refinement parameters are given in Table 1 . The molecular plots were drawn with ORTEP- $3^{46}$ and the polyhedral representations with VESTA. ${ }^{47}$ The topological analyses were conducted with TOPOS. ${ }^{48}$

Luminescence Measurements. Emission spectra were recorded on solid samples using a Horiba-Jobin-Yvon Fluorolog spectrofluorometer. The powdered complex was pressed between two silica plates which were mounted such that the faces were oriented vertically and at $45^{\circ}$ to the incident excitation radiation. An excitation wavelength of $420 \mathrm{~nm}$, a commonly used point although only part of a broad manifold, was used in all cases and the emission was monitored between 450 and $650 \mathrm{~nm}$.

\section{RESULTS AND DISCUSSION}

Synthesis. Complexes 1-14 were synthesized under solvo-hydrothermal conditions (150 ${ }^{\circ} \mathrm{C}$, autogenous pressure), in the presence of $N, N$-dimethylformamide (DMF) as a cosolvent, except for three cases in which either tetrahydrofuran (1), acetonitrile (2), or methanol (11) were used instead. While these three latter cosolvents are absent from the final products, DMF hydrolysis into formic acid and dimethylamine, a frequent occurrence when this solvent is used at elevated temperatures in the presence of metal ions, ${ }^{49}$ results in the presence of dimethylammonium counterions in complexes 5-8 (with guanidinium cations being also present in 5). In the other cases in which the uranyl-containing assembly is not neutral, the counterions are transition metal $\left(\mathrm{Co}^{\mathrm{II}}\right.$, $\mathrm{Cd}^{\mathrm{II}}, \mathrm{Ni}^{\mathrm{II}}, \mathrm{Cu}^{\mathrm{I}}$ or $\mathrm{Zn}^{\mathrm{II}}$ ) or $\mathrm{Pb}^{\mathrm{II}}$ cations, chelated by one to three bipy molecules, so that compounds 
9-14 are heterometallic (Table 2). Only two complexes (1 and 2) were synthesized from the pure trans form of the ligand, as was the only complex previously reported, ${ }^{6}$ the experimental conditions used for the syntheses from the mixture of isomers failing to give any crystalline material. All the others complexes, whether they include only the cis or both cis and trans isomers (in variable proportions), were obtained from the cis/trans mixture. It is notable that no complex obtained from the latter contains only the trans ligand, which, together with the difficulties encountered when working with the pure trans form, suggests that complexes involving the cis isomer are much more amenable to crystallization. It is notable that formation of crystals of complex $\mathbf{8}$ is the usual final outcome in the syntheses involving the mixture of ligand isomers and DMF as a cosolvent; in particular, complexes $3, \mathbf{6}$ and $\mathbf{7}$ could only be obtained in low yield by using a limited heating period, longer ones affording complex 8 instead (see Experimental Section). Such features of solvothermal syntheses of uranyl carboxylates are, in our experience, ${ }^{4,5,32,34,35,37}$ far from abnormal and a basic aspect again reflected in the present work is that even the ratio uranium:ligand in the reaction mixture is not necessarily that of the isolated crystals. The true paucity of data concerning speciation of metal ions and ligands in superheated solvents (especially mixed solvents) necessitates a somewhat empirical approach to the development of solvothermal syntheses and it may be noted that what is reported herein are only the results of successful experiments to provide crystalline products, not the results of many unsuccessful experiments which provided amorphous deposits or no deposit at all.

Crystal Structures. As indicated above, the two complexes [ $\left.\mathrm{UO}_{2}(t-1,4-\mathrm{chdc})\left(\mathrm{H}_{2} \mathrm{O}\right)_{2}\right](\mathbf{1})$ and $\left[\mathrm{UO}_{2}(t-1,4-\mathrm{chdc})\right](2)$ are the only ones in this series to contain only the trans isomer of the ligand. Complex 1 crystallizes in the chiral tetragonal space group $P 4_{3} 2_{1} 2$, with the unique uranyl cation located on a twofold rotation axis (Wyckoff position $4 a$ ); the dicarboxylate ligand, with the 
cyclohexyl ring in the chair conformation and both carboxylate groups equatorial, has also twofold rotation symmetry (Figure 1). The uranium atom is in a hexagonal bipyramidal environment, being chelated by two carboxylate groups and bound to two water molecules in trans positions. The UO bond lengths are in the usual ranges [U-O(oxo) 1.760(4) and 1.764(4) $\AA$; U-O(carboxylate)

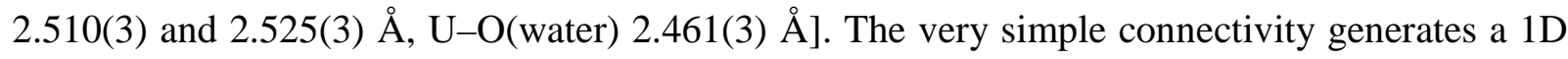
coordination polymer running along the $c$ axis. Each chain is hydrogen bonded to four of its

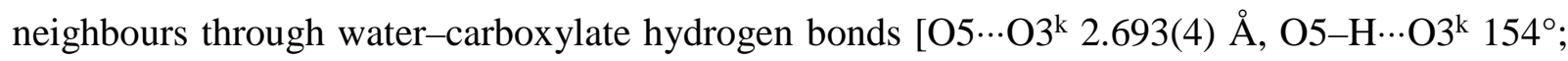

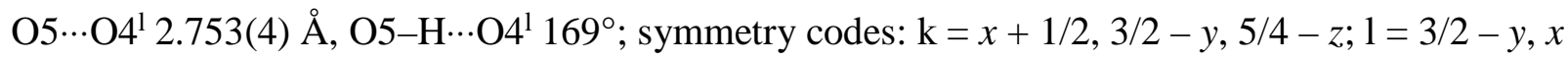
$-1 / 2, z-1 / 4]$, thus generating a 3D assembly. It is this hydrogen bonding which also converts the essentially achiral linear coordination polymer strands into a chiral lattice array (the crystal used for structure determination being however a racemic twin). Viewed down $c$, columns of uranium atoms project onto the $a b$ plane as fused squares of side length $a / 2[=b / 2=4.9397(2) \AA]$. The actual minimum distance between uranium atoms, which are staggered in adjacent columns, is 5.72653(10) $\AA$ and in every group of four columns defining the smallest projected square, the vectors defining this separation form a helical array within the square, right handed in the case of the major component of the particular crystal chosen, as shown in Figure 1. All squares are identical, thus giving rise to the chiral crystal. The Kitaigorodski packing index (KPI) value of 0.75, estimated with PLATON ${ }^{45}$ indicates that no free space is present (usual values for nonporous packings being of the order of 0.65 ). Considering the geometric similarity between $t-1,4-$ chdc $^{2-}$ in the present conformation and the terephthalate dianion, it is no surprise that analogous linear polymeric chains were also found in the uranyl ion complexes of the latter, albeit with different ancillary ligands or with guest molecules. ${ }^{15,17}$ 
Complex $\mathbf{2}$ differs from $\mathbf{1}$ in the absence of the water ligands and its structure is very different as a consequence. The unique uranium atom is located on an inversion center, and the ligand, here also in the chair conformation with equatorial carboxylate groups, is centrosymmetric (Figure 2). The uranium atom is in a square bipyramidal environment, being bound to one oxygen atom of each of four carboxylate groups from four different ligands. The $\mathrm{U}-\mathrm{O}(\mathrm{oxo})$ bond length is $1.728(5) \AA$ and the U-O(carboxylate) bond lengths of 2.289(6) and 2.308(6) $\AA$ match the average value of 2.33(6) $\AA$ for the 29 comparable six-coordinate uranium carboxylate complexes reported in the Cambridge Structural Database (CSD, Version 5.38). ${ }^{50}$ The dicarboxylate ligand is bound to four metal cations in a $\operatorname{bis}\left(\mu_{2}-\kappa^{1} O: \kappa^{1} O^{\prime}\right)$ coordination mode, and both metal and ligand are thus four-fold nodes in the 2D assembly formed, parallel to $\left(\begin{array}{lll}0 & 1 & \overline{1}\end{array}\right)$ and with the point (Schläfli) symbol $\left\{4^{4} \cdot 6^{2}\right\}$ of the common tetragonal Shubnikov lattice. It is notable that a similar topology, with identical uranyl and ligand coordinations, was found in the uranyl ion complex with the enantiopure $(1 R, 2 R)$-trans-1,2-chdc ${ }^{2-}$ ligand. ${ }^{4}$ However, while the sheets in the latter compound are corrugated with the cyclohexyl groups pointing outward, they are planar in $\mathbf{2}$; here also, the terephthalate counterpart, with identical connectivity and topology, has been described. ${ }^{9}$ The layers in $\mathbf{2}$ are packed in bump-to-hollow fashion leaving no solvent-accessible space (KPI 0.70).

The asymmetric unit in complex 3, $\left[\mathrm{UO}_{2}(c-1,4-c h d c)(\mathrm{DMF})\right]$, contains one uranyl ion in general position, one $c-1,2-\mathrm{chdc}^{2-}$ ligand in the chair conformation with one carboxylate group equatorial and the other axial, and one DMF ligand (Figure 3). The uranium atom, in a pentagonal bipyramidal environment, is bound to one chelating and two bridging bidentate carboxylate groups, and to a DMF molecule. The U-O(oxo) bond lengths are 1.764(4) and 1.767(4) $\AA$, the UO(carboxylate) bond lengths 2.439(3) and 2.453(3) $\AA$ for the chelating group, and 2.319(3) and 2.343(3) $\AA$ for the bridging groups, and U-O(DMF) is $2.390(3) \AA$. The uranium atom is thus a 
three-fold node, as is also the dicarboxylate ligand, bound in $\kappa^{2}, \mu_{2}-\kappa^{1} O: \kappa^{1} O^{\prime}$ fashion (for which no counterpart exists in the terephthalate series). The ensuing coordination polymer is $2 \mathrm{D}$ and parallel to $\left(\begin{array}{lll}1 & 0 & \overline{1}\end{array}\right)$, with the $\left\{4.8^{2}\right\}$ point symbol characteristic of the fes Shubnikov net. The sheets are heavily corrugated and packed so as to leave no free space (KPI 0.70). It is notable that, here also, identical connectivity and topology were found in the complexes $\left[\mathrm{UO}_{2}(\operatorname{trans}-1,2-\mathrm{chdc})(\mathrm{L})\right]$, where the dicarboxylate ligand is in its racemic form and L is DMF, THF or $N$-methyl-2-pyrrolidone (NMP). ${ }^{4}$ The fact that no similar complex has been found with terephthalate points to the geometric departure due to one of the carboxylate groups being here in the axial position, thus endowing the ligand with curvature and making it closer in this respect to trans-1,2-chdc ${ }^{2-}$.

Introducing an ancillary ligand in the form of bipy gives the complex $\left[\mathrm{UO}_{2}(c-1,4-\right.$ chdc)(bipy)] (4). The unique uranium atom is in a hexagonal bipyramidal environment, being chelated by two carboxylate groups and bipy (Figure 4) [U-O(oxo) bond lengths $1.761(3)$ and

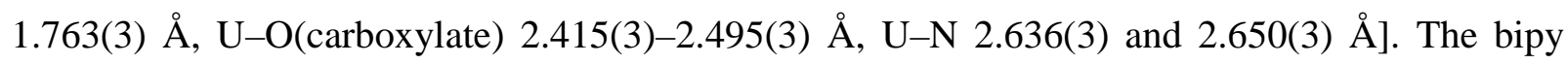
molecule is strongly tilted out of the uranyl equatorial plane [dihedral angle $35.48(8)^{\circ}$ ], thus inducing chirality at the uranium centre, as usual with chelating $\mathrm{N}$-donors. ${ }^{51}$ The dicarboxylate ligand is in the same conformation as in $\mathbf{3}$, and it is bis-chelating as in $\mathbf{1}$. The $1 \mathrm{D}$ coordination polymer parallel to the $b$ axis which is formed assumes a zigzag shape, with the bipy molecules pointing outward on two sides and the uranyl centres being of the same chirality within a given polymer chain; a similar arrangement involving terephthalate and 5,5'-dimethyl-2,2'-bipyridine is found in the CSD. ${ }^{52}$ The bipy molecules of adjacent chains are facing one another with possible $\pi$ stacking interactions [centroid $\cdots$ centroid distances 3.855(3) and 4.237(2) $\AA$, dihedral angles 6.0(2) and $0^{\circ}$, thus resulting in the formation of sheets parallel to $\left(\begin{array}{lll}1 & 0 & \overline{1}\end{array}\right)$; the packing of these sheets leaves no free space (KPI 0.71). 
Complex 5, $\left[\mathrm{C}\left(\mathrm{NH}_{2}\right)_{3}\right]_{3}\left[\mathrm{H}_{2} \mathrm{NMe}_{2}\right]\left[\left(\mathrm{UO}_{2}\right)_{4}(c-1,4-\mathrm{chdc})_{6}\right] \cdot \mathrm{H}_{2} \mathrm{O}$, has the particularity of containing two different organic cations, one (guanidinium) introduced intentionally, and the other (dimethylammonium) generated in situ from DMF hydrolysis (see above). Complex 5 crystallizes in the non-centrosymmetric trigonal space group $R 3 c$, and the asymmetric unit contains two uranium atoms, one of them (U2) located on a threefold rotation axis (Wyckoff position 6a), and two $c$-1,4-chdc ${ }^{2-}$ ligands in the chair conformation (Figure 5). Both uranium atoms are in hexagonal bipyramidal environments, being chelated by three carboxylate groups [U-O(oxo) and $\mathrm{U}_{-}$ O(carboxylate) bond lengths 1.765(4)-1.783(7) $\AA$ and 2.429(4)-2.511(4) , respectively]. The metal cations are thus three-fold nodes while the bis-chelating ligands are simple links in the 3D framework which is built, and which possesses the point symbol $\left\{10^{3}\right\}$ and the topological type MCRLDX (database MOF.ttd ${ }^{48}$ ). When viewed down the $c$ axis, the uranium atoms are arranged in tube-like subunits containing atom U1 and its symmetry equivalents, centered on columns of atom $\mathrm{U} 2$ and its equivalents, the equatorial planes of U1 and U2 making a dihedral angle of $65.13(6)^{\circ}$. Each U2 $(c-1,4-\text { chdc })_{3}$ entity is a threefold symmetric, chiral unit, with the chirality alternating down $c$. The guanidinium cation is involved in six hydrogen bonds with carboxylate oxygen atoms $\left[\mathrm{N} \cdots \mathrm{O} 2.854(6)-3.400(7) \AA, \mathrm{N}-\mathrm{H} \cdots \mathrm{O} \quad 133-170^{\circ}\right]$, and the dimethylammonium cation, which is disordered around the threefold rotation axis, makes two hydrogen bonding

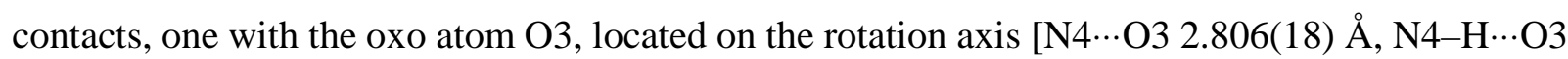
$151^{\circ}$, and the other with the lattice water molecule. The extended hydrogen bonding associated in particular with the guanidinium cation possibly plays a structure-directing effect through bringing six carboxylate groups in suitable position around the cation. Although the packing index cannot be calculated due to disorder, it appears that no channel of significant size is present in the lattice. 
Although synthesized from a mixture of the cis and trans isomers of 1,4-chdcH $\mathrm{C}_{2}, \mathrm{complexes}$ 3-5 contain only the cis isomer, but in several other cases the final compound involves both isomers. This is so for complex 6, $\left[\mathrm{H}_{2} \mathrm{NMe}_{2}\right]_{2}\left[\left(\mathrm{UO}_{2}\right)_{2}(c-1,4-\mathrm{chdc})_{2}(t-1,4-\mathrm{chdc})\right] \cdot \mathrm{DMF} \cdot 2 \mathrm{H}_{2} \mathrm{O}$, in which the asymmetric unit contains two uranyl and two dimethylammonium cations, and three 1,4chdc $^{2-}$ ligands, two of them cis and one trans (Figure 6). As in complex 5, both uranyl cations are chelated by three carboxylate groups [U-O(oxo) bond lengths 1.761(4)-1.775(4) $\AA$, UO(carboxylate) $2.436(3)-2.490(3) \AA]$. The two $c-1,4-\mathrm{chdc}^{2-}$ ligands are in the chair conformation, as in complexes 3-5, and the $t-1,4-\operatorname{chdc}^{2-}$ anion, in the chair conformation with the two carboxylate groups equatorial as in $\mathbf{1}$ and $\mathbf{2}$, is partly disordered (see Experimental Section; the disordered positions, which are badly resolved, would also be roughly compatible with a $c-1,4-$ chdc $^{2-}$ ligand in the boat conformation, which is however a less probable solution). The uranyl cations connected by the $c-1,4-$ chdc $^{2-}$ ligands form linear chains directed along the $\left[\begin{array}{lll}1 & 1 & 0\end{array}\right]$ axis, two such chains being associated by bridging $t-1,4-$ chdc $^{2-}$ ligands to form a ladder-like polymer. The countercations are hydrogen bonded to carboxylate oxygen atoms, and lattice water and DMF molecules $[\mathrm{N} \cdots \mathrm{O}$ $\left.2.676(8)-3.063(6) \AA, \mathrm{N}-\mathrm{H} \cdots \mathrm{O} 115-175^{\circ}\right]$, while the water molecules are hydrogen bond donors to carboxylate groups only [O $\cdots \mathrm{O} 2.754(5)-2.991(6) \AA$, $\left.\mathrm{O}-\mathrm{H} \cdots \mathrm{O} 116-163^{\circ}\right]$, and a 3D network is thus formed (KPI 0.70).

Apart from the absence of free DMF molecules, complex 7, $\left[\mathrm{H}_{2} \mathrm{NMe}_{2}\right]_{2}\left[\left(\mathrm{UO}_{2}\right)_{2}(c-1,4-\right.$ chdc) $\left.(t-1,4-\text { chdc })_{2}\right] \cdot 2 \mathrm{H}_{2} \mathrm{O}$, differs from 6 by a reversal of the cis/trans isomer ratio, $2: 1$ in $\mathbf{6}$ and 1:2 here. The asymmetric unit contains four uranyl ions, two cis and three complete trans ligands, and two halves of centrosymmetric trans ligands (Figure 7). All uranyl cations are tris-chelated by carboxylate groups, as in complex 6 [U-O(oxo) bond lengths 1.749(11)-1.777(12) $\AA$, UO(carboxylate) $2.415(11)-2.503(12) \AA]$, but here a 2D network with honeycomb, graphene-like 
$\left\{6^{3}\right\}$ topology parallel to $\left(\begin{array}{lll}0 & 0 & 1\end{array}\right)$ is formed. The hexanuclear rings are elongated, the distortion with respect to the regular hexagonal shape being due to the presence of the kinked $c-1,4-$ chdc $^{2-}$ ligands; they are sufficiently large $(\sim 22 \AA \times 12 \AA)$, and the network sufficiently undulated, for 3-fold 2D $\rightarrow 2 \mathrm{D}$ parallel interpenetration to occur, as shown in Fig. 7. This kind of entanglement has previously been observed in two uranyl ion complexes, ${ }^{33,39}$ and its Borromean variant is also known. ${ }^{34}$ A 2-fold 2D $\rightarrow$ 2D parallel interpenetrated geometry with terephthalate as only ligand has been reported, ${ }^{8}$ in which the individual networks have the same $\left\{6^{3}\right\}$ topology as found here, with much more regular hexagonal rings $(\sim 23 \AA)$ due to the presence of linear ligands only, and examples of $2 \mathrm{D} \rightarrow 3 \mathrm{D}$ polycatenation, two of them involving honeycomb nets, have lately been described. ${ }^{19}$ More generally, the 2D honeycomb geometry, which is frequently found in uranyl ion complexes, is particularly conducive to the formation of entangled species (and makes for a substantial part of them ${ }^{53}$ ), provided the ligands are of sufficient length, such as is also found, for example, with 2,5-thiophenedicarboxylate, ${ }^{30,35} 4,4^{\prime}$-biphenyldicarboxylate, ${ }^{32}$ or undecane-1,11dicarboxylate, ${ }^{34}$ in the case of uranyl complexes. In comparison with complex $\mathbf{6}$, it appears that the different cis/trans ratio found in $\mathbf{7}$ has a direct bearing on the topology: the tetranuclear rings found in the former are replaced by hexanuclear rings in the latter due to the higher content in the more linear $t-1,4-$ chdc $^{2-}$ ligand which brings about a larger separation between the metal centres $(\sim 11.4$ $\AA$ versus $\sim 8.6 \AA$ ) and is better adapted to the hexagonal ring geometry. The dimethylammonium cations (two of them having twofold rotation symmetry) form hydrogen bonds with carboxylate oxygen atoms or lattice water molecules $\left[\mathrm{N} \cdots \mathrm{O} 2.75(5)-3.15(4) \AA\right.$, $\left.\mathrm{N}-\mathrm{H} \cdots \mathrm{O} 115-165^{\circ}\right]$, the overall packing having a KPI of $\sim 0.65$ (with probably unresolved additional lattice water molecules).

The complex $\left[\mathrm{H}_{2} \mathrm{NMe}_{2}\right]_{2}\left[\left(\mathrm{UO}_{2}\right)_{2}(c, t-1,4-\mathrm{chdc})_{3}\right] \cdot 2.5 \mathrm{H}_{2} \mathrm{O}(\mathbf{8})$ has a formula very similar to that of $\mathbf{7}$, and the cis/trans ratio is probably the same. However, the particular disorder affecting 
the carbon atom of one carboxylate group of one of the ligands and the ring carbon atom attached to it, slightly different from that in $\mathbf{6}$ which affected both carboxylate groups, could indicate the coexistence of the trans isomer in the chair conformation and the cis one in the boat conformation. A more probable situation is that the disorder is analogous to that in $\mathbf{6}$, part of it being unresolved (but suggested by large and strongly anisotropic displacement parameters) and that both components correspond to the trans isomer; this point being however unclear, the specific cis/trans stoichiometry is not indicated in the formula. In any case, this disordered ligand is a linear linker which acts in the same manner as the purely trans isomer. The asymmetric unit contains two uranyl ions, both tris-chelated by carboxylate groups [U-O(oxo) bond lengths $1.728(11)-1.768(10) \AA$, UO(carboxylate) $2.394(10)-2.569(10) \AA]$, one $c$-1,4-chdc ${ }^{2-}$ ligand, two $t-1,4-$ chdc $^{2-}$ ligands with inversion symmetry, and the disordered ligand (Figure 8). The connectivity is however different from that in 7 , and a binodal 3D framework is formed, with the point symbol $\left\{10^{2} .12\right\}\left\{10^{3}\right\}$ corresponding to a subnet of the mbc topological type, and three such nets are interpenetrated with $\left[\begin{array}{lll}0 & 0 & 1\end{array}\right]$ as interpenetration vector, as shown in Figure 8. The subunit formed by U1 and the $c-1,4-$ chdc $^{2-}$ ligands alone is a helical 1D chain running along the $b$ axis, both directions of rotation being present in the lattice since the space group is centrosymmetric. Atom U2 and the two centrosymmetric $t-1,4-\mathrm{chdc}^{2-}$ ligands form linear chains directed along [llll 110$]$ or $\left[\begin{array}{lll}1 & \overline{1} & 0\end{array}\right]$, these being connected to the helical subunits by the disordered ligands so as to form the 3D framework. The dimethylammonium cations are hydrogen bonded to carboxylate groups and lattice water molecules $\left[\mathrm{N} \cdots \mathrm{O} 2.920(19)-3.01(3) \AA ̊, ~ \mathrm{~N}-\mathrm{H} \cdots \mathrm{O} 122-166^{\circ}\right]$.

While complexes 1-8 are homometallic, all those described in the following are heterometallic. The two complexes $\left[\mathrm{M}(\text { bipy })_{3}\right]\left[\left(\mathrm{UO}_{2}\right)_{2}(c-1,4-\mathrm{chdc})_{3}\right] \cdot 1.5 \mathrm{H}_{2} \mathrm{O}$, with $\mathrm{M}=\mathrm{Co}(\mathbf{9})$ or Cd (10) are isomorphous and they crystallize in the cubic Sohncke space group $P 2{ }_{1} 3$. All metal 
atoms are located on threefold rotation axes (Wyckoff position 4a), the two independent uranium atoms being tris-chelated by carboxylate groups and the 3d-block metal cation being chelated by three bipy molecules (Figures 9 and 10), all with unremarkable bond lengths [U-O(oxo) 1.751(9)-

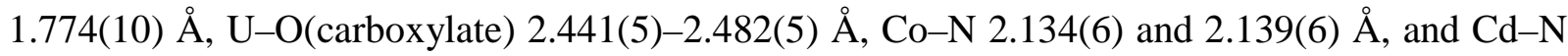
2.342(5) and 2.356(5) $\AA$ ]. The unique $c-1,4-\operatorname{chdc}^{2-}$ ligand is in the chair conformation as usual, but there is some difference in geometry between 9 and 10: the dihedral angles between the average cyclohexyl ring plane and the two carboxylate planes are $26.0(8)$ and $89.5(6)^{\circ}$ in $\mathbf{9}$, and $75.9(7)$ and $79.1(8)^{\circ}$ in $\mathbf{1 0}$, and the dihedral angles between the two carboxylate groups are $63.5(8)^{\circ}$ in 9 and $79.4(9)^{\circ}$ in $\mathbf{1 0}$, this having however no effect on the connectivity. The uninodal 3D framework formed in both cases has the point symbol $\left\{10^{3}\right\}$ and the topological type srs (corresponding to the net of silicon positions in $\mathrm{SrSi}_{2}$ ), a common chiral net topology for MOFs based on triangular building units. ${ }^{54-56}$ The interactions within the lattice are predominantly electrostatic in this ionic compound, ${ }^{57}$ but it may however be noted that several contacts between aromatic protons of the bipy molecules and oxo or carboxylate oxygen atoms are possibly indicative of weak $\mathrm{CH} \cdots \mathrm{O}$

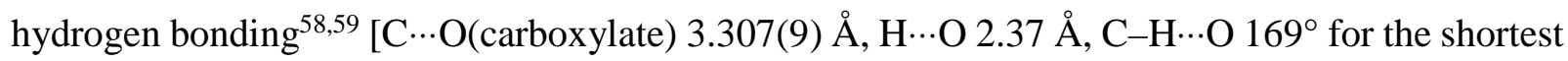
of these bonds in 9; $\mathrm{C} \cdots \mathrm{O}$ (oxo) 3.124(9) $\AA, \mathrm{H} \cdots \mathrm{O} 2.52 \AA, \mathrm{C}-\mathrm{H} \cdots \mathrm{O} 122^{\circ}$ in 10]. In both cases, at least one of these interactions appears prominently in the Hirshfeld surface ${ }^{60}$ drawn with CrystalExplorer. ${ }^{61}$ More generally, such interactions have been found in several uranyl complexes involving $\left[\mathrm{M}(\mathrm{bipy} / \mathrm{phen})_{3}\right]^{2+}$ cations (phen $=1,10$-phenanthroline $)$, and they seem to be a favourite mode of interaction of the latter..$^{34,35,37,62-64}$ It may be surmised that the chiral $\left[\mathrm{M}(\text { bipy })_{3}\right]^{2+}$ cation exerts a structure-directing effect on the formation of the chiral framework in these complexes and induces a particular chirality in it, in a manner similar to that possibly resulting in the formation of 
triple-stranded uranyl-based helicates. ${ }^{63}$ Both 9 and 10, like 1, provide examples of complexes which undergo "spontaneous resolution".

The complex obtained with $\mathrm{Ni}^{\mathrm{II}}$ cations, $\left[\mathrm{Ni}(\mathrm{bipy})_{3}\right]_{2}\left[\left(\mathrm{UO}_{2}\right)_{4}(c-1,4-\mathrm{chdc})_{2}(t-1,4-\right.$ chdc) $\left.\left(\mathrm{NO}_{3}\right)_{6}\right] \cdot 2 \mathrm{H}_{2} \mathrm{O}(\mathbf{1 1})$, is different from 9 and $\mathbf{1 0}$, which may be an effect of the different organic cosolvent, i.e. methanol instead of DMF. There are two uranyl ions in the asymmetric unit, one of them (U1) chelated by two carboxylate groups and one nitrate ion, and the other by one carboxylate

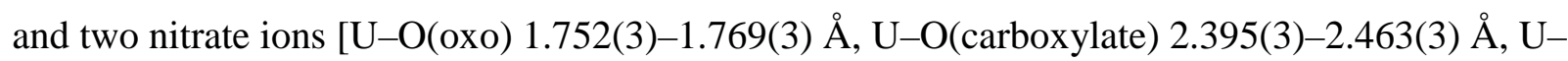
$\mathrm{O}$ (nitrate) $2.479(3)-2.530(3) \AA]$ (Figure 11). This is the only example in this series of retention of nitrate ions in the final product. The $\mathrm{Ni}^{\mathrm{II}}$ cation is chelated by three bipy molecules, with $\mathrm{Ni}-\mathrm{N}$ bond lengths of 2.060(3)-2.098(3) ̊. Both ligands are in the chair conformation, $t-1,4-$ chdc $^{2-}$ being centrosymmetric. The presence of the terminal nitrate groups prevents polymerization, and a tetranuclear, tetra-anionic complex is formed instead, the single instance of such a $0 \mathrm{D}$ species in this series (it is however notable that a tetranuclear uranyl complex akin to the present one was described in the case of 1,7-heptanedioic ligands ${ }^{37}$ ). The linear geometry of the central trans isomer linker and the kinked one of the two lateral cis ligands result in the assembly having an S-shape, one bipy ligand from a counterion being included in each curved part. Here also, apart from the dominant Coulombic forces, weak $\mathrm{CH} \cdots \mathrm{O}$ hydrogen bonding interactions, involving hydrogen atoms in bipy molecules and oxo, carboxylate or nitrate oxygen atoms, may be present; they are revealed by examination of the Hirshfeld surface, part of which is shown, as a representative

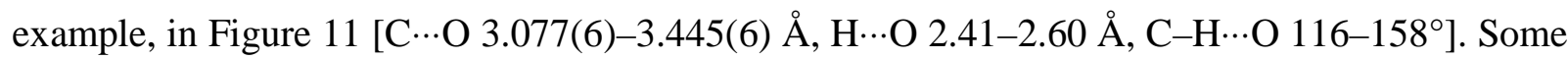
interactions are also mediated by the lattice water molecules, which are donors in $\mathrm{OH} \cdots \mathrm{O}$ bonds to carboxylate groups [O $\cdots \mathrm{O} 2.907(6)$ and $2.980(6) \AA$, $\mathrm{O}-\mathrm{H} \cdots \mathrm{O} 129$ and $151^{\circ}$ ], and acceptors in 
$\mathrm{CH} \cdots \mathrm{O}$ bonds from the cations. With a KPI of 0.71 , the packing does not contain significant free spaces.

The complex $\left[\mathrm{Cu}(\text { bipy })_{2}\right]_{2}\left[\left(\mathrm{UO}_{2}\right)_{2}(c-1,4-\mathrm{chdc})_{2}(t-1,4-\mathrm{chdc})\right] \cdot 2 \mathrm{H}_{2} \mathrm{O}(\mathbf{1 2})$ differs from the other complexes in this series by the reduction of the d-block metal cation, initially $\mathrm{Cu}^{\mathrm{II}}$, into $\mathrm{Cu}^{\mathrm{I}}$, a phenomenon previously observed in syntheses performed under (solvo-)hydrothermal conditions. ${ }^{64,65}$ The asymmetric unit contains two uranyl ions, each of them chelated by three carboxylate groups, cis and trans ligands in the same ratio as in complexes $\mathbf{6}$ and 11, and two $\left[\mathrm{Cu} \text { (bipy) }{ }_{2}\right]^{+}$counterions (Figure 12 ). The environment of the uranium atom is unremarkable [U$\mathrm{O}$ (oxo) $1.756(7)-1.778(7) \AA$, U-O(carboxylate) $2.414(8)-2.509(7) \AA]$, as is that of copper(I), which is in a distorted tetrahedral environment, as usual for this cation ${ }^{66}[\mathrm{Cu}-\mathrm{N} 1.995(8)-2.084(9)$ $\AA$ A d dihedral angles between bipy molecules $62.87(18)$ and $\left.78.34(15)^{\circ}\right]$. All the dicarboxylate ligands are in the chair conformation, and the coexistence of linear trans and kinked cis ligands results in the formation of a uninodal 3D framework with the same point symbol $\left\{10^{3}\right\}$ as in $\mathbf{5 , 9}$ and $\mathbf{1 0}$, but pertaining to a third topological type, ths $\left(\mathrm{ThSi}_{2}\right)$, which is, with srs, the most common 3-connected 3D net. ${ }^{54}$ The srs and ths nets differ by their vertex symbols, $\left[10_{5} \cdot 10_{5} \cdot 10_{5}\right]$ and $\left[10_{2} \cdot 10_{4} \cdot 10_{4}\right]$, respectively (while the vertex symbol for the binodal net in $\mathbf{5}$, $\left[10 \cdot 10_{3} \cdot 10_{3}\right] \cdot\left[10_{3} \cdot 10_{3} \cdot 10_{3}\right]$, is not a common one). Two 3D nets are interpenetrated in complex 12, with $\left[\begin{array}{lll}1 & 0 & 0\end{array}\right]$ as interpenetration vector, as shown in Figure 12. It is notable that 2-fold interpenetration of $3 \mathrm{D}$ nets with the ths topology has also been encountered in the uranyl ion complex with 4,4',4"-(phenylsilanetriyl)tribenzoate, a tripodal ligand. ${ }^{38}$ When viewed down the $a$ axis, the packing in 12 displays large hexagonal channels $(\sim 12-14 \AA)$ which are occupied by the counterions. Being arranged into columns, the counterions may possibly be involved in two $\pi$ stacking interactions [centroid $\cdots$ centroid distances 4.149(6) and 4.235(6) $\AA$, dihedral angle 33.0(5) ${ }^{\circ}$ 
for both], but these do not appear to be greater than dispersion from Hirshfeld surface analysis. Two $\mathrm{CH} \cdots \pi$ interactions involving hydrogen atoms of cyclohexyl and bipy groups may be present

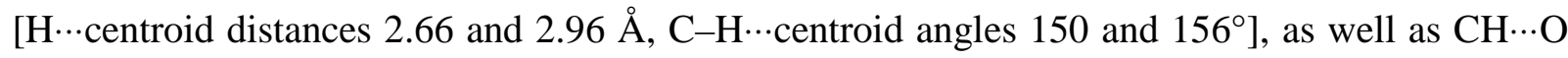
hydrogen bonds between bipy hydrogen atoms and oxo or carboxylate oxygen atoms $[\mathrm{C} \cdots \mathrm{O}$ 3.094(13)-3.560(13) $\AA$, $\mathrm{H} \cdots \mathrm{O} 2.42-2.62 \AA, \mathrm{C}-\mathrm{H} \cdots \mathrm{O} 128-173^{\circ}$ ]. No significant porosity is present in the lattice (KPI 0.68).

The last complex in this series to involve a d-block metal cation is $\left[\mathrm{Zn}(\text { bipy })_{3}\right]\left[\left(\mathrm{UO}_{2}\right)_{2}(c-\right.$ 1,4-chdc) $\left.)_{3}\right] \cdot 4 \mathrm{H}_{2} \mathrm{O}(\mathbf{1 3})$, and, as in complexes $\mathbf{9}$ and $\mathbf{1 0}$, only the cis isomer of the dicarboxylate ligand is present. The asymmetric unit contains two uranyl cations chelated by three carboxylate groups [U-O(oxo) 1.760(5)-1.774(4) Å, U-O(carboxylate) 2.423(5)-2.539(4) $\mathrm{A}$ ], three ligands in chair conformation, and the $\left[\mathrm{Zn}(\text { bipy })_{3}\right]^{2+}$ cation $[\mathrm{Zn}-\mathrm{N} 2.144(5)-2.167(5) \AA ̊ 0$ (Figure 13). While the uranyl ions in $\mathbf{9}$ and $\mathbf{1 0}$ are located on threefold symmetry axes, they are in general position here, and the arrangement of the ligands around the metal centre are slightly different for the two atoms: for U1, two ligands point toward the same side of the equatorial plane and the third toward the other side, and for $\mathrm{U} 2$, two are on the same side and the third straddles the equatorial plane. As a consequence of this difference, the coordination polymer does not form a 3D framework as in 9 and 10, but a uninodal 2D network parallel to $\left(\begin{array}{lll}1 & 0 & \overline{1}\end{array}\right)$, with the point symbol $\left\{4.8^{2}\right\}$ and the common fes topological type. The layers are rather thick $(\sim 14 \AA)$ since the rings are strongly inclined with respect to the sheet average plane, so that, when viewed down the $b$ axis, the curved rings with four vertices appear to define channels in which the counterions are partly embedded, being located in the inter-ring spaces. Two aromatic rings from adjacent counterions are possibly engaged in a parallel-displaced $\pi$-stacking interaction (but this appears to be no greater than dispersion in the Hirshfeld surface) [centroid $\cdots$ centroid distance 4.023(3) $\AA$, dihedral angle $0^{\circ}$ ] and there may be 
two intralayer $\mathrm{CH} \cdots \pi$ interactions involving hydrogen atoms of a cyclohexyl ring $[\mathrm{H} \cdots$ centroid distances 2.79 and $2.88 \AA$ A, C-H $\cdots$ centroid angles 154 and $126^{\circ}$ ]. The lattice water molecules are involved in hydrogen bonds among themselves and with carboxylate groups, thus linking adjacent sheets $\left[\mathrm{O} \cdots \mathrm{O} 2.667(13)-3.116(10) \AA, \mathrm{O}-\mathrm{H} \cdots \mathrm{O} 120-169^{\circ}\right]$, the latter being tightly packed in bumpto-hollow fashion, thus leaving no free space (KPI 0.68). Here also, Hirshfeld surface examination shows that $\mathrm{CH} \cdots \mathrm{O}$ hydrogen bonds may play some role in the finer details of the packing of anions

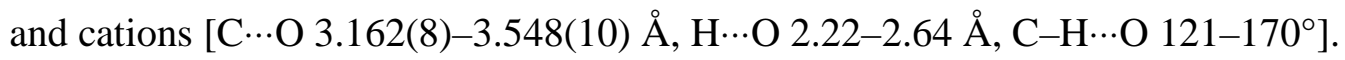

The last complex, $\left[\mathrm{UO}_{2} \mathrm{~Pb}_{2}(c-1,4-\mathrm{chdc})(t-1,4-\mathrm{chdc})_{2}(\text { bipy })_{2}\right](\mathbf{1 4})$, is the only one in the series to involve a p-block metal cation, $\mathrm{Pb}^{\mathrm{II}}$, and it is also the only one in which the additional metal cation is bound to carboxylate groups and thus part of the polymeric assembly. The asymmetric unit contains a single uranyl ion chelated by one carboxylate group and bound to three more carboxylate oxygen atoms from three different ligands, the uranium atom being thus in a pentagonal bipyramidal environment [U-O(oxo) 1.787(3) and 1.791(4) $\AA$, U-O(carboxylate) 2.495(4) and 2.500(4) $\AA$ for the chelating group, and 2.323(4)-2.340(4) $\AA$ for the others]; it contains also two $\mathrm{Pb}^{\mathrm{II}}$ cations and one cis and three trans (two of them centrosymmetric) ligands in the chair conformation (Figure 14). While one of the centrosymmetric trans ligands displays the usual geometry with two equatorial carboxylate groups, these are both axial in the other ligand (containing $\mathrm{O} 13$ and O14), which is unique in the present series. Both lead(II) atoms are chelated by one carboxylate group and one bipy molecule, and they are bound to three more carboxylate oxygen atoms, with $\mathrm{Pb}-\mathrm{O} / \mathrm{N}$ bond lengths in the range $2.447(4)-2.811(4) \AA$; both of them make two longer contacts (not represented in Figure 14 for clarity) with one carboxylate oxygen atom [3.355(4) $\AA$ ] and the uranyl oxo atom O1 [3.561(4) $\AA]$ in the case of Pb1, and with two carboxylate oxygen atoms pertaining to groups already bonded in monodentate fashion [3.239(4) and 3.498(4) 
$\AA]$ in the case of $\mathrm{Pb} 2$. These latter contacts may represent very weak interactions at best (in particular, uranyl oxo bonding to $\mathrm{Pb}^{\mathrm{II}}$ with a much shorter distance of $2.999(4) \AA$ has been reported ${ }^{67}$ ) and, if they are disregarded, both $\mathrm{Pb}^{\mathrm{II}}$ cations are in seven-coordinate environments with a geometry of the tetragonal base-trigonal base type ${ }^{68}$ and a distinctly hemidirected character, possibly as a consequence of the lead(II) lone pair. ${ }^{69}$ The coordination modes of the carboxylate groups are either chelating and bridging $\left(\mu_{2}-\kappa^{1} O: \kappa^{2} O, O^{\prime}\right)$ or bridging bidentate $\left(\mu_{2}-\kappa^{1} O: \kappa^{1} O^{\prime}\right)$, and they are bound to either one uranium and one lead atom, or two lead atoms; overall, each ligand connects four metal centres (one $\mathrm{U}$ and three $\mathrm{Pb}$, two $\mathrm{U}$ and two $\mathrm{Pb}$, or four $\mathrm{Pb}$ ). A 7-nodal 3D framework is formed, with the point symbol $\left\{4^{2} \cdot 6^{2} \cdot 8^{2}\right\}_{2}\left\{4^{2} \cdot 6^{3} .8\right\}_{3}\left\{4^{2} .8^{4}\right\}$. Uranyl ions and its ligands alone form 1D chains directed along the $a$ axis, while lead(II) and its ligands generate a 3D framework on their own. Two parallel-displaced $\pi$-stacking interactions may be present [centroid $\cdots$ centroid distances 3.726(3) and 3.950(3) A, dihedral angles 4.7(3) and 22.0(3) ${ }^{\circ}$, as well as one $\mathrm{CH} \cdots \pi$ interaction involving a hydrogen atom from bipy $[\mathrm{H} \cdots$ centroid distance $2.51 \AA$, C$\mathrm{H} \cdots$ centroid angle $\left.172^{\circ}\right]$, and several $\mathrm{CH} \cdots \mathrm{O}$ hydrogen bonds [C $\cdots \mathrm{O} 3.052(7)-3.490(7) \AA$, $\mathrm{H} \cdots \mathrm{O}$ 2.29-2.63 $\left.\AA, \mathrm{C}-\mathrm{H} \cdots \mathrm{O} 122-165^{\circ}\right]$. The framework is very compact and has no solvent-accessible space (KPI 0.72).

Luminescence properties. Emission spectra in the solid state were recorded at room temperature under excitation at a wavelength of $420 \mathrm{~nm}$ for the complexes which could be obtained pure and in sufficient amount, i.e. the homometallic complexes 1, 2, 5 and $\mathbf{8}$, and all the heterometallic complexes 9-14. Complete quenching of uranyl luminescence is observed for the heterometallic complexes $\mathbf{9}, 12$ and $\mathbf{1 4}$, containing $\mathrm{Co}^{\mathrm{II}}, \mathrm{Cu}^{\mathrm{I}}$ and $\mathrm{Pb}^{\mathrm{II}}$ cations, respectively. This is a frequent phenomenon in the case of open-shell d-block metal ions such as $\mathrm{Co}^{\mathrm{II}}$ and is attributed 
to energy transfer to a $\mathrm{d}-\mathrm{d}$ excited state followed by non-radiative decay, ${ }^{12,29,32,35,63,64,70}$ while energy transfer to an isolated $\mathrm{Cu}^{\mathrm{I}}$ centre, possibly involving a d-s excited state, would be expected to give rise at most to a weak $\mathrm{Cu}^{\mathrm{I}}$ emission. ${ }^{71}$ Quenching due to the presence of lead(II) has been previously observed, ${ }^{67,72}$ although it is not general, ${ }^{4,49}$ and its origins are obscure. In all the other cases, the vibronic progression corresponding to the $S_{11} \rightarrow S_{00}$ and $S_{10} \rightarrow S_{0 v}(v=0-4)$ electronic transitions $^{73}$ is apparent, with four or five intense and well-resolved peaks, as shown in Figure 15, the positions of these emission bands being dependent on the nature and number of donor atoms in the uranyl equatorial plane. ${ }^{74,75}$ Uranyl luminescence is largely quenched in the $\mathrm{Ni}^{\mathrm{II}}$-containing complex 11, as well as in the homometallic complex 5. In all the complexes giving well-resolved spectra, the uranium atom is eight-coordinate, except for $\mathbf{2}$, in which it is six-coordinate; the peak positions vary only in a narrow range within the series, with the four stronger ones located at $477-$ 483, 497-503, 518-525, and 544-549 $\mathrm{nm}$. Similar values have previously been found in other complexes with three chelating carboxylate groups ${ }^{4,5,12,26,37,49,64,76-80}$ (although this is not genera $^{35,67}$ ). While the peak positions for the square bipyramidal complex 2 fall within these ranges, different, red-shifted values have recently been found in a complex with $(1 R, 2 R)$-trans-1,2cyclohexanedicarboxylate with a similar coordination environment (main maxima at 501, 524, 548 and $575 \mathrm{~nm}){ }^{4}$ further comparison is however hampered by the scarcity of uranyl carboxylate complexes displaying this geometry alone. The average vibronic splitting energies for the $S_{10} \rightarrow$ $S_{0 v}$ transitions are in the range $819(17)-868(17) \mathrm{cm}^{-1}$ for the whole series, the largest value being for complex 1; these values are usual for uranyl complexes with carboxylates. ${ }^{4,5,12,35,37,73,81,82}$

So as to get a visual representation of the dependence of the peaks positions upon the geometry of the uranyl equatorial environment, the positions of the four main peaks $\left[S_{10} \rightarrow S_{0 v}(v\right.$ $=0-3)]$ have been plotted in Figure 16 for a series of 46 complexes involving various 
polycarboxylate ligands (including also the present results)., ${ }^{4,5,12,32,35,37,49,51,64,67,72,77-80,83-85}$ All these complexes are from our own work, so that all measures have been performed using the same apparatus and in exactly the same conditions, and only well resolved spectra of complexes having only one kind of equatorial environment have been considered; the precision of the measurements can be estimated at $\pm 2 \mathrm{~nm}$. The complexes are separated into four groups according to the number and nature of equatorial donors, $\mathrm{O}_{6}, \mathrm{O}_{4} \mathrm{~N}_{2}, \mathrm{O}_{5}$ or $\mathrm{O}_{4}$, and the complexes are sorted within each group in the order of red-shift of the lowest wavelength emission peak, so that shifts in the positions of the three other peaks between different complexes reveal slight variations of the splitting energy. As a general trend, it appears that the tris-chelated $\mathrm{O}_{6}$ environment is associated to the most blueshifted positions, and the $\mathrm{O}_{5}$ environment to the most red-shifted ones, the shift spanning a range of $\sim 20 \mathrm{~nm}$ for each peak. The most red-shifted positions for one peak are close to the most blueshifted ones for the peak immediately to its right, which gives a somewhat misleading appearance of continuity between curves for adjacent peaks. Replacement of one chelating carboxylate by a chelating $\mathrm{N}$-donor such as bipy or phen, thus giving the $\mathrm{O}_{4} \mathrm{~N}_{2}$ equatorial environment, has no marked effect. It is notable that several $\mathrm{O}_{6}$ complexes depart from the usual trend, with positions that cover a large part of the range of $\mathrm{O}_{5}$ complexes; this is the case in particular with tetrahydrofurantetracarboxylic acid, in which two ether oxygen atoms replace a carboxylate group ${ }^{67}$ and also with 2,5-thiophenedicarboxylate, ${ }^{35}$ possibly reflecting a variation in the strength of the ligand induced by the presence of sulfur, as well as with three other ligands in which the origin of the shift is not obvious. ${ }^{32,49,64}$ Finally, while one of the complexes with $\mathrm{O}_{4}$ environment gives the most red-shifted values of all, ${ }^{4}$ which is in keeping with the general tendency, the other, complex 2 , is clearly anomalous, with values typical of the $\mathrm{O}_{6}$ environment; it is however notable that a similar shift of $\sim 20 \mathrm{~nm}$ between two closely related $\mathrm{O}_{4}$ complexes has previously been 
reported. ${ }^{9}$ Obviously, even if a general trend appears here, within a family of complexes all involving carboxylate ligands, it is nevertheless important to stress that the coordination number is only one factor at play, the ligand strength in particular exerting an influence. ${ }^{74,75}$ Some carboxylate complexes studied by other groups fit well in the present series, ${ }^{15,16,18,19,26,86-88}$ but a different evolution of peak positions with respect to number of donors has been found in a family of pyrazine- or pyridine-containing carboxylates. ${ }^{89}$ It is known that a red-shift of uranyl emission peaks positions is related to an increase of donor strength in the equatorial plane, inducing a decrease in uranyl oxo bond order, ${ }^{74,90}$ which would suggest that the reduced crowding in the equatorial plane, and the associated shorter bond lengths, in $\mathrm{O}_{5}$ species with respect to $\mathrm{O}_{6}$ ones must result in an overall donor strength increase in the former.

\section{CONCLUSIONS}

The synthesis, crystal structure and, when possible, luminescence properties of 14 uranyl ion complexes containing the 1,4-cyclohexanedicarboxylate ligand in either its pure trans or cis forms, or as mixtures in varying proportions, have been described; these two ligand isomers have very different shapes, linear for the trans form when the two carboxylate groups are in equatorial position, as is most often the case, and curved for the cis one, with one axial and one equatorial carboxylate group. It is relevant to note here that where a mixture of the cis and trans isomers of 1,3-cyclohexanedicarboxylic acid was used to prepare uranyl ion complexes, it resulted also in a crystalline species where both isomers were present in the one lattice, ${ }^{91}$ although this remains a relatively rare circumstance. Neutral 1D and 2D assemblies can be obtained with either the cis or trans isomers of 1,4-chdc ${ }^{2-}$ in their pure form, but, while these are the only complexes with the trans isomer which crystallized under the conditions used, the cis isomer gives also anionic species which crystallize as $2 \mathrm{D}$ nets or 3D frameworks, depending on the nature of the counterion (Table 
2). Anionic complexes only were obtained with the mixture of isomers, among which are three interpenetrated species, either 2D or 3D. Since uranyl-containing entangled networks have not been reviewed to date, a summary of all cases known, to the best of our knowledge, is given in Table 3 . The cases are subdivided into interpenetrated (i.e. with no change in dimensionality) and polycatenated (with dimensionality increase), and the dimensionality notation proposed by Batten is used for the latter. ${ }^{21}$ The divergent, ditopic nature of 1,4-chdc ${ }^{2-}$, and the elongated shape of the trans isomer in particular, are favorable to the formation of large rings, these in their turn promoting entanglement, as in the parent aromatic terephthalate ligand, for which several cases of interpenetration are known, ${ }^{8,16}$ and $2 \mathrm{D} \rightarrow 3 \mathrm{D}$ polycatenated species were recently reported. ${ }^{19}$ The three interpenetration cases reported here are threefold $2 \mathrm{D}$ or $3 \mathrm{D}$, and twofold $3 \mathrm{D}$, the two former involving the $\mathrm{H}_{2} \mathrm{NMe}_{2}{ }^{+}$cation, and the latter $\left[\mathrm{Cu}(\text { bipy })_{2}\right]^{+}$(several other cases of uranyl-containing coordination polymers with $\left[\mathrm{M}(\text { bipy/phen })_{n}\right]^{+/ 2+}(n=2$ or 3$)$ counterions have been found which display interpenetration ${ }^{34}$ or polycatenation ${ }^{32,35}$ ). Overall, with its two isomeric forms and its great sensitivity to the experimental conditions (particularly to the counterions present), 1,4-chdc ${ }^{2-}$ appears to be a ligand of choice for the synthesis of uranyl ion complexes displaying a wide range of architectures. The uranyl emission properties of ten of the present complexes were measured, with complete quenching for three heterometallic species and well-resolved spectra in the other cases; together with those of other polycarboxylate complexes previously reported and measured under the same conditions, they provide evidence of a general trend, with the maxima for the complexes with $\mathrm{O}_{6}$ or $\mathrm{O}_{4} \mathrm{~N}_{2}$ equatorial environments being in most cases blue-shifted with respect to those of complexes with an $\mathrm{O}_{5}$ environment. 


\section{ASSOCIATED CONTENT}

\section{Supporting Information}

The Supporting Information is available free of charge on the ACS Publications website at DOI:. X-ray crystallographic information. (CIF)

\section{AUTHOR INFORMATION}

\section{Corresponding Authors}

*E-mail: pierre.thuery@cea.fr. (P.T.)

\section{Notes}

The authors declare no competing financial interest.

\section{REFERENCES}

1. Andrews, M. B.; Cahill, C. L. Uranyl Bearing Hybrid Materials: Synthesis, Speciation, and SolidState Structures. Chem. Rev. 2013, 113, 1121-1136.

2. Loiseau, T.; Mihalcea, I.; Henry, N.; Volkringer, C. The Crystal Chemistry of Uranium Carboxylates. Coord. Chem. Rev. 2014, 266-267, 69-109.

3. Su, J.; Chen, J. S. MOFs of Uranium and the Actinides. Struct. Bond. 2015, 163, 265-296.

4. Thuéry, P.; Harrowfield, J. Coordination Polymers and Cage-Containing Frameworks in Uranyl Ion Complexes with rac- and $(1 R, 2 R)$-trans-1,2-Cyclohexanedicarboxylates: Consequences of Chirality. Inorg. Chem. 2017, 56, 1455-1469.

5. Thuéry, P.; Harrowfield, J. Tetrahedral and Cuboidal Clusters in Complexes of Uranyl and Alkali or Alkaline-Earth Metal Ions with rac- and (1R,2R)-trans-1,2-Cyclohexanedicarboxylate. Cryst. Growth Des. 2017, 17, 2881-2892. 
6. Mihalcea, I.; Falaise, C.; Volkringer, C.; Henry, N.; Loiseau, T. Room Temperature Crystallization of Trichlorodioxouranate $\left[\mathrm{UO}_{2} \mathrm{Cl}_{3}(\mathrm{~L})\right]$ Species in Molecular Assemblies Involving Aliphatic Dicarboxylate Linkers. Inorg. Chem. Commun. 2014, 44, 63-66.

7. Yu, Z. T.; Liao, Z. L.; Jiang, Y. S.; Li, G. H.; Chen, J. S. Water-Insoluble Ag-U-Organic Assemblies with Photocatalytic Activity. Chem. - Eur. J. 2005, 11, 2642-2650.

8. Go, Y. B.; Wang, X.; Jacobson A. J. (6,3)-Honeycomb Structures of Uranium(VI) Benzenedicarboxylate Derivatives: The Use of Noncovalent Interactions to Prevent Interpenetration. Inorg. Chem. 2007, 46, 6594-6600.

9. Mihalcea, I.; Henry, N.; Bousquet, T.; Volkringer, C.; Loiseau. T. Six-Fold Coordinated Uranyl Cations in Extended Coordination Polymers. Cryst. Growth Des. 2012, 12, 4641-4648.

10. Thangavelu, S. G.; Andrews, M. B.; Pope, S. J. A.; Cahill, C. L. Synthesis, Structures, and Luminescent Properties of Uranyl Terpyridine Aromatic Carboxylate Coordination Polymers. Inorg. Chem. 2013, 52, 2060-2069.

11. Kerr, A. T.; Kumalah, S. A.; Holman, K. T.; Butcher, R. J.; Cahill, C. L. Uranyl Coordination Polymers Incorporating $\eta^{5}$-Cyclopentadienyliron-Functionalized $\eta^{6}$-Phthalate Metalloligands: Syntheses, Structures and Photophysical Properties. J. Inorg. Organomet. Polym. Mater. 2014, 24, $128-136$.

12. Thuéry, P.; Harrowfield, J. Uranyl-Organic Frameworks with Polycarboxylates: Unusual Effects of a Coordinating Solvent. Cryst. Growth Des. 2014, 14, 1314-1323.

13. Li, H. H.; Zeng, X. H.; Wu, H. Y.; Jie, X.; Zheng, S. T.; Chen, Z. R. Incorporating Guest Molecules into Honeycomb Structures Constructed from Uranium(VI)-Polycarboxylates: Structural Diversities and Photocatalytic Activities for the Degradation of Organic Dye. Cryst. Growth Des. 2015, 15, 10-13. 
14. Chen, F.; Wang, C. Z.; Li, Z. J.; Lan, J. H.; Ji, Y. Q.; Chai, Z. F. New Three-Fold Interpenetrated Uranyl Organic Framework Constructed by Terephthalic Acid and Imidazole Derivative. Inorg. Chem. 2015, 54, 3829-3834.

15. Gao, X.; Wang, C.; Shi, Z. F.; Song, J.; Bai, F. Y.; Wang, J. X.; Xing, Y. H. A Family of UranylAromatic Dicarboxylate (pht-, ipa-, tpa-) Framework Hybrid Materials: Photoluminescence, Surface Photovoltage and Dye Adsorption. Dalton Trans. 2015, 44, 11562-11571.

16. Zhang, Y.; Karatchevtseva, I.; Bhadbhade, M.; Tran, T. T.; Aharonovich, I.; Fanna, D. J.; Shepherd, N. D.; Lu, K.; Li, F.; Lumpkin, G. R. Solvothermal Synthesis of Uranium(VI) Phases with Aromatic Carboxylate Ligands: A Dinuclear Complex with 4-Hydroxybenzoic Acid and a 3D Framework with Terephthalic Acid. J. Solid State Chem. 2016, 234, 22-28.

17. Thangavelu, S. G.; Cahill, C. L. A Family of Uranyl Coordination Polymers Containing O-Donor Dicarboxylates and Trispyridyltriazine Guests. Cryst. Growth Des. 2016, 16, 42-50.

18. Wu, H. Y.; Li, H. H.; Chen, Z. R. Synthesis, Crystal Structure and Characterization of the HostGuest Type UOF. Chinese J. Struct. Chem. 2017, 36, 679-688.

19. Mei, L.; Wang, C. Z.; Zhu, L. Z.; Gao, Z. Q.; Chai, Z. F.; Gibson, J. K.; Shi, W. Q. Exploring New Assembly Modes of Uranyl Terephthalate: Templated Syntheses and Structural Regulation of a Series of Rare 2D $\rightarrow$ 3D Polycatenated Frameworks. Inorg. Chem. 2017, 56, 7694-7706.

20. Batten, S. R.; Robson, R. Interpenetrating Nets: Ordered, Periodic Entanglement. Angew. Chem. Int. Ed. 1998, 37, 1460-1494.

21. Batten, S. R. Topology of Interpenetration. CrystEng Comm 2001, 18, 1-7.

22. Carlucci, L.; Ciani, G.; Proserpio, D. M. Polycatenation, Polythreading and Polyknotting in Coordination Network Chemistry. Coord. Chem. Rev. 2003, 246, 247-289. 
23. Carlucci, L.; Ciani, G.; Proserpio, D. M.; Mitina, T. G.; Blatov, V. A. Entangled Two-Dimensional Coordination Networks: A General Survey. Chem. Rev. 2014, 114, 7557-7580.

24. Gong, Y. N.; Zhong, D. C.; Lu, T. B. Interpenetrating Metal-Organic Frameworks. CrystEngComm 2016, 18, 2596-2606.

25. Alexandrov, E. V.; Blatov, V. A.; Proserpio, D. M. How 2-Periodic Coordination Networks are Interweaved: Entanglement Isomerism and Polymorphism. CrystEngComm 2017, 19, 1993-2006.

26. Borkowski, L. A.; Cahill, C. L. Crystal Engineering with the Uranyl Cation II. Mixed Aliphatic Carboxylate/Aromatic Pyridyl Coordination Polymers: Synthesis, Crystal Structures, and Sensitized Luminescence. Cryst. Growth Des. 2006, 6, 2248-2259.

27. Lis, S.; Glatty, Z.; Meinrath, G.; Kubicki, M. Poly (Isonicotinic Acid N-Oxide-Isonicotinate-NOxide-Chloro-Uranyl): The Interpenetrating Grids Created by Coordination and Hydrogen Bonds. J. Chem. Crystallogr. 2010, 40, 646-649.

28. Wu, H. Y.; Wang, R. X.; Yang, W.; Chen, J.; Sun, Z. M.; Li, J.; Zhang, H. 3-Fold-Interpenetrated Uranium-Organic Frameworks: New Strategy for Rationally Constructing Three-Dimensional Uranyl Organic Materials. Inorg. Chem. 2012, 51, 3103-3107.

29. Kerr, A. T.; Cahill, C. L. Postsynthetic Rearrangement/Metalation as a Route to Bimetallic Uranyl Coordination Polymers: Syntheses, Structures, and Luminescence. Cryst. Growth Des. 2014, 14, $1914-1921$.

30. Thangavelu, S. G.; Butcher, R. J.; Cahill, C. L. Role of N-Donor Sterics on the Coordination Environment and Dimensionality of Uranyl Thiophenedicarboxylate Coordination Polymers. Cryst. Growth Des. 2015, 15, 3481-3492.

31. Wang, Y.; Liu, Z.; Li, Y.; Bai, Z.; Liu, W.; Wang, Y.; Xu, X.; Xiao, C.; Sheng, D.; Diwu, J.; Su, J.; Chai, Z.; Albrecht-Schmitt, T. E.; Wang, S. Umbellate Distortions of the Uranyl Coordination 
Environment Result in a Stable and Porous Polycatenated Framework that can Effectively Remove Cesium from Aqueous Solutions. J. Am. Chem. Soc. 2015, 137, 6144-6147.

32. Thuéry, P.; Harrowfield, J. Structural Variations in the Uranyl/4,4'-Biphenyldicarboxylate System. Rare Examples of 2D $\rightarrow$ 3D Polycatenated Uranyl-Organic Networks. Inorg. Chem. 2015, $54,8093-8102$.

33. Mei, L.; Wu, Q. Y.; An, S. W.; Gao, Z. Q.; Chai, Z. F.; Shi, W. Q. Silver Ion-Mediated Heterometallic Three-Fold Interpenetrating Uranyl-Organic Framework. Inorg. Chem. 2015, 54, 10934-10945.

34. Thuéry, P. From Helicates to Borromean Links: Chain Length Effect in Uranyl Ion Complexes of Aliphatic $\alpha, \omega$-Dicarboxylates. Cryst. Growth Des. 2016, 16, 546-549.

35. Thuéry, P.; Harrowfield, J. Counter-Ion Control of Structure in Uranyl Ion Complexes with 2,5Thiophenedicarboxylate. CrystEngComm 2016, 18, 1550-1562.

36. An, S. W.; Mei, L.; Hu, K. Q.; Xia, C. Q.; Chai, Z. F.; Shi, W. Q. The Templated Synthesis of a Unique Type of Tetra-Nuclear Uranyl-Mediated Two-Fold Interpenetrating Uranyl-Organic Framework. Chem. Commun. 2016, 52, 1641-1644.

37. Thuéry, P.; Rivière, E.; Harrowfield, J. Counterion-Induced Variations in the Dimensionality and Topology of Uranyl Pimelate Complexes. Cryst. Growth Des. 2016, 16, 2826-2835.

38. Liu, C.; Gao, C. Y.; Yang, W.; Chen, F. Y.; Pan, Q. J.; Li, J.; Sun, Z. M. Entangled Uranyl Organic Frameworks with (10,3)- $b$ Topology and Polythreading Network: Structure, Luminescence, and Computational Investigation. Inorg. Chem. 2016, 55, 5540-5548.

39. Zhao, R.; Mei, L.; Wang, L.; Chai, Z. F.; Shi, W. Q. Copper/Zinc-Directed Heterometallic UranylOrganic Polycatenating Frameworks: Synthesis, Characterization, and Anion-Dependent Structural Regulation. Inorg. Chem. 2016, 55, 10125-10134. 
40. Hu, K. Q.; Jiang, X.; Wang, C. Z.; Mei, L.; Xie, Z. N.; Tao, W. Q.; Zhang, X. L.; Chai, Z. F.; Shi, W. Q. Solvent-Dependent Synthesis of Porous Anionic Uranyl-Organic Frameworks Featuring a Highly Symmetrical $(3,4)$-Connected $c t n$ or bor Topology for Selective Dye Adsorption. Chem. Eur. J. 2017, 23, 529-532.

41. Hooft, R. W. W. COLLECT, Nonius BV: Delft, The Netherlands, 1998.

42. Otwinowski, Z.; Minor, W. Processing of X-Ray Diffraction Data Collected in Oscillation Mode. Methods Enzymol. 1997, 276, 307-326.

43. Sheldrick, G. M. SHELXT - Integrated Space-Group and Crystal-Structure Determination. Acta Crystallogr., Sect. A 2015, 71, 3-8.

44. Sheldrick, G. M. Crystal Structure Refinement with SHELXL. Acta Crystallogr., Sect. C 2015, $71,3-8$.

45. Spek, A. L. Structure Validation in Chemical Crystallography. Acta Crystallogr., Sect. D 2009, $65,148-155$.

46. Farrugia, L. J. WinGX and ORTEP for Windows: an Update. J. Appl. Crystallogr. 2012, 45, 849854.

47. Momma, K.; Izumi, F. VESTA: a Three-Dimensional Visualization System for Electronic and Structural Analysis. J. Appl. Crystallogr. 2008, 41, 653-658.

48. Blatov, V. A. TOPOS, Samara State University, Russia, 2004.

49. Thuéry, P.; Harrowfield, J. Modulation of the Structure and Properties of Uranyl Ion Coordination Polymers Derived from 1,3,5-Benzenetriacetate by Incorporation of $\mathrm{Ag}(\mathrm{I})$ or $\mathrm{Pb}(\mathrm{II})$. Inorg. Chem. 2016, 55, 6799-6816 and references therein.

50. Groom, C. R.; Bruno, I. J.; Lightfoot, M. P.; Ward, S. C. The Cambridge Structural Database. Acta Crystallogr., Sect. B 2016, 72, 171-179. 
51. Thuéry, P.; Harrowfield, J. Anchoring Flexible Uranyl Dicarboxylate Chains through Stacking Interactions of Ancillary Ligands on Chiral U(VI) Centres. CrystEngComm 2016, 18, 3905-3918. 52. Thangavelu, S. G.; Cahill, C. L. CSD Communication (refcode WUKVUV).

53. Alexandrov, E. V.; Blatov, V. A.; Proserpio, D. M. How 2-Periodic Coordination Networks are Interweaved: Entanglement Isomerism and Polymorphism. CrystEngComm 2017, 19, 1993-2006.

54. O’Keeffe, M.; Eddaoudi, M.; Li, H.; Reineke, T.; Yaghi, O. M. Frameworks for Extended Solids: Geometrical Design Principles. J. Solid State Chem. 2000, 152, 3-20.

55. Delgado Friedrichs, O.; O’Keeffe, M.; Yaghi, O. M. Three-Periodic Nets and Tilings: Regular and Quasiregular Nets. Acta Crystallogr., Sect. A 2003, 59, 22-27.

56. Wright, P. A. Microporous Framework Solids. RSC Materials Monographs, The Royal Society of Chemistry, Cambridge, 2008.

57. Gavezzotti, A. The "Sceptical Chymist": Intermolecular Doubts and Paradoxes. CrystEngComm 2013, 15, 4027-4035.

58. Taylor, R.; Kennard, O. Crystallographic Evidence for the Existence of $\mathrm{C}-\mathrm{H} \cdots \mathrm{O}, \mathrm{C}-\mathrm{H} \cdots \mathrm{N}$, and CH‥Cl Hydrogen Bonds. J. Am. Chem. Soc. 1982, 104, 5063-5070.

59. Desiraju, G. R. The C-H‥O Hydrogen Bond: Structural Implications and Supramolecular Design. Acc. Chem. Res. 1996, 29, 441-449.

60. Spackman, M. A.; Jayatilaka, D. Hirshfeld Surface Analysis. CrystEngComm 2009, 11, 19-32.

61. Wolff, S. K.; Grimwood, D. J.; McKinnon, J. J.; Turner, M. J.; Jayatilaka, D.; Spackman, M. A. CrystalExplorer, University of Western Australia, 2012.

62. Thuéry, P. Interlocked Aromatic Species: Crystal Structure and Hirshfeld Surface Analysis of the Uranyl Ion Complex of 3-(Pyrimidin-2-yl)benzoate with Ni(phen) $3^{2+}$ Counter-Ions. Inorg. Chem. Commun. 2015, 59, 25-27. 
63. Thuéry, P.; Harrowfield, J. A New Form of Triple-Stranded Helicate Found in Uranyl Complexes of Aliphatic $\alpha, \omega$-Dicarboxylates. Inorg. Chem. 2015, 54, 10539-10541.

64. Thuéry, P.; Harrowfield, J. Uranyl Ion Complexes with Long-Chain Aliphatic $\alpha, \omega$-Dicarboxylates and 3d-Block Metal Counterions. Inorg. Chem. 2016, 55, 2133-2145.

65. Weng, Z.; Zhang, Z. H.; Olds, T.; Sterniczuk, M.; Burns, P. C. Copper(I) and Copper(II) Uranyl Heterometallic Hybrid Materials. Inorg. Chem. 2014, 53, 7993-7998.

66. Raithby, P. R.; Shields, G. P.; Allen, F. H.; Motherwell, W. D. S. Structure Correlation Study of Four-Coordinate Copper(I) and (II) Complexes. Acta Crystallogr., Sect. B 2000, 56, 444-454.

67. Thuéry, P.; Harrowfield, J. Tetrahydrofurantetracarboxylic Acid: An Isomerizable FrameworkForming Ligand in Homo- and Heterometallic Complexes with $\mathrm{UO}_{2}{ }^{2+}, \mathrm{Ag}^{+}$, and $\mathrm{Pb}^{2+}$. Cryst. Growth Des. 2016, 16, 7083-7093.

68. Moseley, P. T. Aspects of the Structural Chemistry of Lanthanide and Actinide Compounds. In Inorganic Chemistry, Series Two, Vol.7: Lanthanides and Actinides; Bagnall, K. W., Ed.; Butterworths: London, and University Park Press: Baltimore, 1975; Chapter 3, pp. 65-110.

69. Shimoni-Livny, L.; Glusker, J. P.; Bock, C. W. Lone Pair Functionality in Divalent Lead Compounds. Inorg. Chem. 1998, 37, 1853-1867.

70. Alsobrook, A. N.; Zhan, W.; Albrecht-Schmitt, T. E. Use of Bifunctional Phosphonates for the Preparation of Heterobimetallic 5f-3d Systems. Inorg. Chem. 2008, 47, 5177-5183.

71. Ford, P. C.; Cariati, E.; Bourassa, J. Photoluminescence Properties of Multinuclear Copper(I) Compounds. Chem. Rev. 1999, 99, 3625-3647.

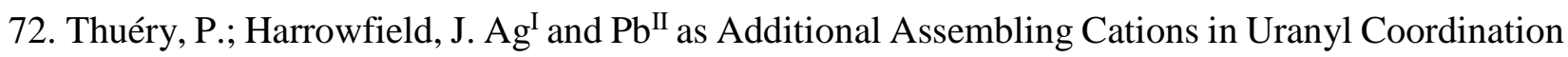
Polymers and Frameworks. Cryst. Growth Des. 2017, 17, 2116-2130. 
73. Brachmann, A.; Geipel, G.; Bernhard, G.; Nitsche, H. Study of Uranyl(VI) Malonate Complexation by Time Resolved Laser-Induced Fluorescence Spectroscopy (TRLFS). Radiochim. Acta 2002, 90, 147-153.

74. Redmond, M. P.; Cornet, S. M.; Woodall, S. D.; Whittaker, D.; Collison, D.; Helliwell, M.; Natrajan, L. S. Probing the Local Coordination Environment and Nuclearity of Uranyl(VI) Complexes in Non-Aqueous Media by Emission Spectroscopy. Dalton Trans. 2011, 40, 39143926.

75. Carter, K. P.; Kalaj, M.; Cahill, C. L. Probing the Influence of N-Donor Capping Ligands on Supramolecular Assembly in Molecular Uranyl Materials. Eur. J. Inorg. Chem. 2016, 126-137.

76. Thuéry, P.; Harrowfield, J. Chiral One- to Three-Dimensional Uranyl-Organic Assemblies from (1R,3S)-(+)-Camphoric Acid. CrystEng Comm 2014, 16, 2996-3004.

77. Thuéry, P.; Harrowfield, J. Uranyl Ion Complexes with all-cis-1,3,5-Cyclohexanetricarboxylate: Unexpected Framework and Nanotubular Assemblies. Cryst. Growth Des. 2014, 14, 4214-4225.

78. Thuéry, P.; Harrowfield, J. Two-Dimensional Assemblies in f-Element Ion $\left(\mathrm{UO}_{2}{ }^{2+}, \mathrm{Yb}^{3+}\right)$ Complexes with Two Cyclohexyl-Based Polycarboxylates. Polyhedron 2015, 98, 5-11.

79. Thuéry, P.; Rivière, E.; Harrowfield, J. Uranyl and Uranyl-3d Block Cation Complexes with 1,3Adamantanedicarboxylate: Crystal Structures, Luminescence, and Magnetic Properties. Inorg. Chem. 2015, 54, 2838-2850.

80. Thuéry, P.; Harrowfield, J. Solvent Effects in Solvo-Hydrothermal Synthesis of Uranyl Ion Complexes with 1,3-Adamantanediacetate. CrystEngComm 2015, 17, 4006-4018.

81. Surbella, R. G., III; Andrews, M. B.; Cahill, C. L. Self-assembly of $\left[\mathrm{UO}_{2} \mathrm{X}_{4}\right]^{2-}(\mathrm{X}=\mathrm{Cl}, \mathrm{Br})$ Dianions with $\gamma$ Substituted Pyridinium Cations: Structural Systematics and Fluorescence Properties. J. Solid State Chem. 2016, 236, 257-271. 
82. Martin, N. P.; Falaise, C.; Volkringer, C.; Henry, N.; Farger, P.; Falk, C.; Delahaye, E.; Rabu, P.; Loiseau, T. Hydrothermal Crystallization of Uranyl Coordination Polymers Involving an Imidazolium Dicarboxylate Ligand: Effect of $\mathrm{pH}$ on the Nuclearity of Uranyl-Centered Subunits. Inorg. Chem. 2016, 55, 8697-8705.

83. Thuéry, P.; Masci, B.; Harrowfield, J. Complexation of Uranyl and Rare-Earth Ions by a Fluorinated Tetracarboxylate. Formation of a Layered Assembly and Three-Dimensional Frameworks. Cryst. Growth Des. 2013, 13, 3216-3224.

84. Thuéry, P.; Harrowfield, J. Uranyl Ion Complexes with 1,1'-Biphenyl-2,2',6,6'-tetracarboxylic Acid: Structural and Spectroscopic Studies of One- to Three-Dimensional Assemblies. Inorg. Chem. 2015, 54, 6296-6305.

85. Thuéry, P.; Harrowfield, J. Variations on the Honeycomb Topology: From Triangular- and Square-Grooved Networks to Tubular Assemblies in Uranyl Tricarballylate Complexes. Cryst. Growth Des. 2017, 17, 963-966.

86. Frisch, M.; Cahill, C. L. Synthesis, Structure and Fluorescent Studies of Novel Uranium Coordination Polymers in the Pyridinedicarboxylic Acid System. Dalton Trans. 2006, 4679-4690. 87. Luo, G. G.; Lin, L. R.; Huang, R. B.; Zheng, L. S. Synthesis, Crystal Structure and Optical Properties of $\left[\mathrm{Ag}\left(\mathrm{UO}_{2}\right)_{3}(\mathrm{OAc})_{9}\right]\left[\mathrm{Zn}\left(\mathrm{H}_{2} \mathrm{O}\right)_{4}\left(\mathrm{CH}_{3} \mathrm{CH}_{2} \mathrm{OH}\right)_{2}\right]$ : A Novel Compound Containing Closed-Shell $3 \mathrm{~d}^{10}, 4 \mathrm{~d}^{10}$ and $5 \mathrm{~d}^{10}$ Metal Ions. Dalton Trans. 2007, 3868-3870.

88. Carter, K. P.; Kalaj, M.; Cahill, C. L. Harnessing Uranyl Oxo Atoms via Halogen Bonding Interactions in Molecular Uranyl Materials Featuring 2,5-Diiodobenzoic Acid and N-donor Capping Ligands. Inorg. Chem. Front. 2017, 4, 65-78.

89. Severance, R. C.; Vaughn, S. A.; Smith, M. D.; zur Loye, H. C. Structures and Luminescent Properties of New Uranyl-Based Hybrid Materials. Sol. State Sci. 2011, 13, 1344-1353. 
90. Natrajan, L. S. Developments in the Photophysics and Photochemistry of Actinide Ions and their Coordination Compounds. Coord. Chem. Rev. 2012, 256, 1583-1603.

91. Thuéry, P. Two Novel Uranyl-Organic Frameworks with Cyclohexane-1,3-Dicarboxylate Ligands. CrystEngComm 2009, 11, 232-234. 
Table 1. Crystal Data and Structure Refinement Details

\begin{tabular}{|c|c|c|c|c|c|c|c|}
\hline & 1 & 2 & 3 & 4 & 5 & 6 & 7 \\
\hline chemical formula & $\mathrm{C}_{8} \mathrm{H}_{14} \mathrm{O}_{8} \mathrm{U}$ & $\mathrm{C}_{8} \mathrm{H}_{10} \mathrm{O}_{6} \mathrm{U}$ & $\mathrm{C}_{11} \mathrm{H}_{17} \mathrm{NO}_{7} \mathrm{U}$ & $\mathrm{C}_{18} \mathrm{H}_{18} \mathrm{~N}_{2} \mathrm{O}_{6} \mathrm{U}$ & $\mathrm{C}_{53} \mathrm{H}_{88} \mathrm{~N}_{10} \mathrm{O}_{33} \mathrm{U}_{4}$ & $\mathrm{C}_{31} \mathrm{H}_{57} \mathrm{~N}_{3} \mathrm{O}_{19} \mathrm{U}_{2}$ & $\mathrm{C}_{28} \mathrm{H}_{50} \mathrm{~N}_{2} \mathrm{O}_{18} \mathrm{U}_{2}$ \\
\hline$M\left(\mathrm{~g} \mathrm{~mol}^{-1}\right)$ & 476.22 & 440.19 & 513.29 & 596.37 & 2345.45 & 1251.85 & 1178.76 \\
\hline cryst syst & tetragonal & triclinic & monoclinic & monoclinic & trigonal & triclinic & monoclinic \\
\hline space group & $P 4_{3} 2_{1} 2$ & $P_{1}$ & $P 2_{1} / n$ & $C 2 / c$ & $R 3 c$ & $P \overline{1}$ & $C 2 / c$ \\
\hline$a(\AA)$ & $9.8794(2)$ & $5.2458(8)$ & $10.4507(4)$ & $20.7782(12)$ & $25.5726(2)$ & $11.0583(6)$ & $33.764(2)$ \\
\hline$b(\AA)$ & $9.8794(2)$ & $6.6155(11)$ & $11.6086(8)$ & 15.4983(10) & $25.5726(2)$ & $12.4583(7)$ & $16.2336(5)$ \\
\hline$c(\AA)$ & $11.5842(3)$ & $7.5996(10)$ & $12.2553(8)$ & $13.2569(8)$ & $19.0833(2)$ & $15.1292(9)$ & $29.3892(15)$ \\
\hline$\alpha(\mathrm{deg})$ & 90 & $90.354(4)$ & 90 & 90 & 90 & $81.442(3)$ & 90 \\
\hline$\beta(\operatorname{deg})$ & 90 & $91.472(4)$ & $105.657(4)$ & $122.283(3)$ & 90 & $87.336(3)$ & $100.032(3)$ \\
\hline$\gamma(\mathrm{deg})$ & 90 & $104.606(3)$ & 90 & 90 & 120 & $88.505(2)$ & 90 \\
\hline$V\left(\AA^{3}\right)$ & $1130.65(5)$ & $255.10(7)$ & $1431.62(15)$ & $3609.2(4)$ & $10807.7(2)$ & $2058.5(2)$ & $15862.3(13)$ \\
\hline$Z$ & 4 & 1 & 4 & 8 & 6 & 2 & 16 \\
\hline$D_{\text {calcd }}\left(\mathrm{g} \mathrm{cm}^{-3}\right)$ & 2.798 & 2.865 & 2.381 & 2.195 & 2.162 & 2.020 & 1.974 \\
\hline$\mu(\operatorname{Mo~K} \alpha)\left(\mathrm{mm}^{-1}\right)$ & 14.385 & 15.912 & 11.367 & 9.033 & 9.056 & 7.935 & 8.229 \\
\hline$F(000)$ & 872 & 198 & 952 & 2240 & 6648 & 1200 & 8960 \\
\hline reflns collcd & 37439 & 13862 & 73692 & 61986 & 136707 & 115146 & 195832 \\
\hline indep reflns & 1462 & 966 & 2706 & 3422 & 6199 & 7824 & 15008 \\
\hline obsd reflns $[I>2 \sigma(I)]$ & 1403 & 966 & 2284 & 2928 & 5997 & 6370 & 10398 \\
\hline$R_{\text {int }}$ & 0.014 & 0.022 & 0.058 & 0.028 & 0.018 & 0.065 & 0.061 \\
\hline params refined & 80 & 70 & 183 & 244 & 326 & 521 & 920 \\
\hline$R_{1}$ & 0.016 & 0.029 & 0.028 & 0.023 & 0.019 & 0.030 & 0.073 \\
\hline$w R_{2}$ & 0.040 & 0.080 & 0.063 & 0.051 & 0.047 & 0.070 & 0.171 \\
\hline$S$ & 1.212 & 1.102 & 1.050 & 1.048 & 1.025 & 1.081 & 1.093 \\
\hline$\Delta \rho_{\min }\left(\mathrm{e} \AA^{-3}\right)$ & -1.24 & -1.42 & -1.66 & -0.71 & -0.85 & -1.35 & -3.47 \\
\hline$\Delta \rho_{\max }\left(\mathrm{e} \AA^{-3}\right)$ & 0.41 & 2.42 & 0.96 & 0.91 & 0.41 & 1.25 & 4.06 \\
\hline Flack parameter & $0.635(14)$ & & & & $-0.007(7)$ & & \\
\hline
\end{tabular}

\begin{tabular}{|c|c|c|c|c|c|c|c|}
\hline & 8 & 9 & 10 & 11 & 12 & 13 & 14 \\
\hline chemical formula & $\mathrm{C}_{28} \mathrm{H}_{51} \mathrm{~N}_{2} \mathrm{O}_{18.5} \mathrm{U}_{2}$ & $\mathrm{C}_{54} \mathrm{H}_{57} \mathrm{CoN}_{6} \mathrm{O}_{17.5} \mathrm{U}_{2}$ & $\mathrm{C}_{54} \mathrm{H}_{57} \mathrm{CdN}_{6} \mathrm{O}_{175} \mathrm{U}_{2}$ & $\mathrm{C}_{84} \mathrm{H}_{82} \mathrm{~N}_{18} \mathrm{Ni}_{2} \mathrm{O}_{40} \mathrm{U}_{4}$ & $\mathrm{C}_{64} \mathrm{H}_{66} \mathrm{Cu}_{2} \mathrm{~N}_{8} \mathrm{O}_{18} \mathrm{U}_{2}$ & $\mathrm{C}_{54} \mathrm{H}_{62} \mathrm{~N}_{6} \mathrm{O}_{20} \mathrm{U}_{2} \mathrm{Zn}$ & $\mathrm{C}_{44} \mathrm{H}_{46} \mathrm{~N}_{4} \mathrm{O}_{14} \mathrm{~Pb}_{2} \mathrm{U}$ \\
\hline$M\left(\mathrm{~g} \mathrm{~mol}^{-1}\right)$ & 1187.76 & 1605.04 & 1658.51 & 3053.21 & 1838.38 & 1656.52 & 1507.26 \\
\hline cryst syst & monoclinic & cubic & cubic & triclinic & monoclinic & monoclinic & monoclinic \\
\hline space group & $P 2_{1} / n$ & $P 2{ }_{1} 3$ & $P 2{ }_{1} 3$ & $P \overline{1}$ & $P c$ & $P 2_{1} / n$ & $P 2_{1} / c$ \\
\hline$a(\AA)$ & $14.7946(5)$ & $17.9583(2)$ & $18.0725(2)$ & $9.0917(6)$ & $8.2701(3)$ & $14.8140(8)$ & $11.5531(9)$ \\
\hline$b(\AA)$ & $11.7088(3)$ & $17.9583(2)$ & $18.0725(2)$ & $13.9416(10)$ & $14.8223(6)$ & $13.9212(5)$ & $11.4052(10)$ \\
\hline$c(\AA)$ & $23.2413(7)$ & $17.9583(2)$ & $18.0725(2)$ & $20.9702(11)$ & $26.6956(9)$ & $28.5654(16)$ & $33.8218(18)$ \\
\hline$\alpha(\mathrm{deg})$ & 90 & 90 & 90 & $103.600(4)$ & 90 & 90 & 90 \\
\hline$\beta(\operatorname{deg})$ & $96.463(3)$ & 90 & 90 & $97.167(4)$ & $95.453(2)$ & $92.058(3)$ & $97.770(5)$ \\
\hline$\gamma(\operatorname{deg})$ & 90 & 90 & 90 & $108.243(3)$ & 90 & 90 & 90 \\
\hline$V\left(\AA^{3}\right)$ & $4000.4(2)$ & $5791.56(19)$ & $5902.8(2)$ & $2396.3(3)$ & $3257.6(2)$ & $5887.2(5)$ & $4415.6(6)$ \\
\hline$Z$ & 4 & 4 & 4 & 1 & 2 & 4 & 4 \\
\hline$D_{\text {calcd }}\left(\mathrm{g} \mathrm{cm}^{-3}\right)$ & 1.972 & 1.841 & 1.866 & 2.116 & 1.874 & 1.869 & 2.267 \\
\hline$\mu(\mathrm{Mo} \mathrm{K} \alpha)\left(\mathrm{mm}^{-1}\right)$ & 8.159 & 5.936 & 5.904 & 7.220 & 5.678 & 5.971 & 11.339 \\
\hline$F(000)$ & 2260 & 3096 & 3180 & 1456 & 1784 & 3208 & 2824 \\
\hline reflns collcd & 136750 & 90471 & 96674 & 135973 & 108206 & 234579 & 121504 \\
\hline indep reflns & 7577 & 3657 & 3732 & 9076 & 12042 & 11149 & 8372 \\
\hline obsd reflns $[I>2 \sigma(I)]$ & 5796 & 3492 & 3660 & 7562 & 11470 & 8375 & 6943 \\
\hline$R_{\text {int }}$ & 0.042 & 0.018 & 0.013 & 0.043 & 0.044 & 0.055 & 0.045 \\
\hline params refined & 509 & 248 & 248 & 667 & 848 & 748 & 586 \\
\hline$R_{1}$ & 0.059 & 0.025 & 0.023 & 0.028 & 0.030 & 0.041 & 0.027 \\
\hline$w R_{2}$ & 0.144 & 0.063 & 0.059 & 0.062 & 0.075 & 0.085 & 0.058 \\
\hline$S$ & 1.165 & 1.065 & 1.094 & 1.035 & 1.033 & 1.020 & 1.049 \\
\hline$\Delta \rho_{\min }\left(\mathrm{e} \AA^{-3}\right)$ & -1.66 & -0.76 & -0.52 & -1.35 & -0.52 & -1.21 & -1.08 \\
\hline$\Delta \rho_{\max }\left(\mathrm{e} \AA^{-3}\right)$ & 2.32 & 0.40 & 0.58 & 0.53 & 0.81 & 0.78 & 0.88 \\
\hline Flack parameter & & $-0.014(10)$ & $-0.003(8)$ & & $-0.003(5)$ & & \\
\hline
\end{tabular}


Table 2. Isomeric Form of the 1,4-chdc ${ }^{2-}$ Ligand, Countercations and Dimensionality in

\section{Complexes 1-14}

\begin{tabular}{llll}
\hline Compound & Isomers present & \multicolumn{1}{c}{ Countercations } & \multicolumn{1}{c}{ Dimensionality } \\
\hline $\mathbf{1}$ & trans & \\
$\mathbf{2}$ & trans & $1 \mathrm{D}$ \\
$\mathbf{3}$ & cis & $2 \mathrm{D}$ \\
$\mathbf{4}$ & cis & $2 \mathrm{D}$ \\
$\mathbf{5}$ & cis & $\mathrm{C}\left(\mathrm{NH}_{2}\right)_{3}{ }^{+}, \mathrm{H}_{2} \mathrm{NMe}_{2}{ }^{+}$ & $1 \mathrm{D}$ \\
$\mathbf{6}$ & cis + trans & $\mathrm{H}_{2} \mathrm{NMe}_{2}{ }^{+}$ & $3 \mathrm{D}$ \\
$\mathbf{7}$ & cis + trans & $\mathrm{H}_{2} \mathrm{NMe}_{2}{ }^{+}$ & $1 \mathrm{D}$ \\
$\mathbf{8}$ & cis + trans & $\mathrm{H}_{2} \mathrm{NMe}_{2}{ }^{+}$ & $2 \mathrm{D}, 3$-fold interpenetration \\
$\mathbf{9}$ & cis & $\mathrm{Co}(\text { bipy })_{3}{ }^{2+}$ & $3 \mathrm{D}, 3$-fold interpenetration \\
$\mathbf{1 0}$ & cis & $\mathrm{Cd}(\text { bipy })_{3}{ }^{2+}$ & $3 \mathrm{D}$ \\
$\mathbf{1 1}$ & cis + trans & $\mathrm{Ni}(\text { bipy })_{3}{ }^{2+}$ & $3 \mathrm{D}$ \\
$\mathbf{1 2}$ & cis + trans & $\mathrm{Cu}(\text { bipy })_{2}{ }^{+}$ & 0D, tetranuclear \\
$\mathbf{1 3}$ & cis & $\mathrm{Zn}(\text { bipy })_{3}{ }^{2+}$ & $3 \mathrm{D}, 2$-fold interpenetration \\
$\mathbf{1 4}$ & cis + trans & $\mathrm{Pb}(\text { bipy })^{2+}($ complexed $)$ & $3 \mathrm{D}$ \\
\hline
\end{tabular}


Table 3. Uranyl-Containing Entangled Networks

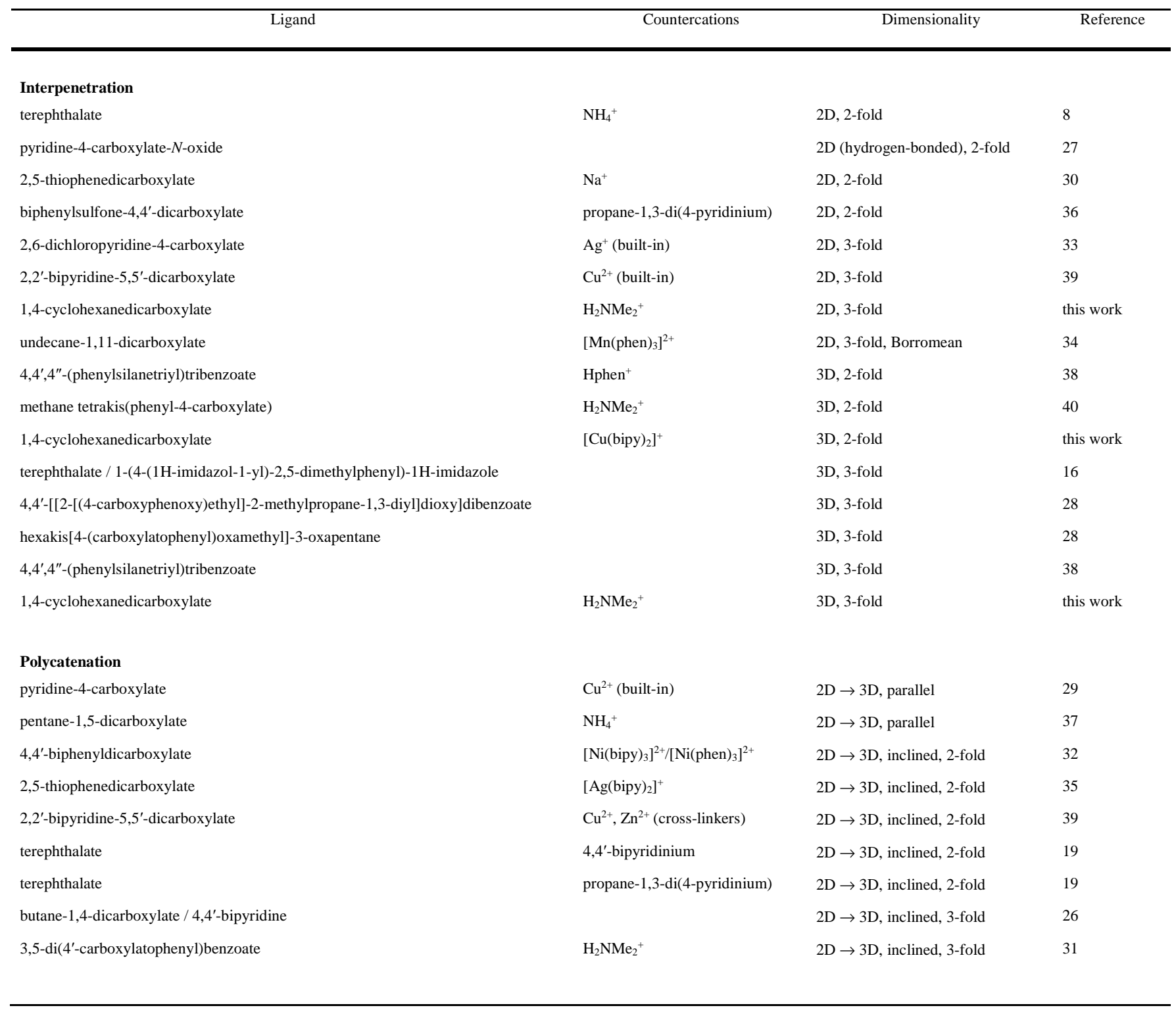




\section{Figure Captions}

Figure 1. Top left: View of complex 1. Displacement ellipsoids are drawn at the 50\% probability level and carbon-bound hydrogen atoms are omitted. Symmetry codes: $\mathrm{i}=y, x, 1-$ $z ; \mathrm{j}=y, x, 2-z$. Top right: View of the $1 \mathrm{D}$ polymer with uranium coordination polyhedra colored yellow, as in all subsequent figures, and hydrogen atoms omitted. Bottom left: View showing the chirality-inducing hydrogen bonding between adjacent chains. Symmetry code: $\mathrm{k}$ $=x+1 / 2,3 / 2-y, 5 / 4-z$. Bottom right: View of the packing.

Figure 2. Top: View of complex 2. Displacement ellipsoids are drawn at the $50 \%$ probability level. Symmetry codes: $\mathrm{i}=-x, 2-y, 2-z ; \mathrm{j}=x-1, y, z ; \mathrm{k}=1-x, 2-y, 2-z ; 1=x+1, y, z$; $\mathrm{m}=1-x, 1-y, 1-z ; \mathrm{n}=x, y-1, z-1$. Middle: View of the 2D assembly. Bottom: Packing with layers viewed edge-on. Hydrogen atoms are omitted in all views.

Figure 3. Top left: View of complex 3. Displacement ellipsoids are drawn at the $40 \%$ probability level. Symmetry codes: $\mathrm{i}=x+1 / 2,3 / 2-y, z+1 / 2 ; \mathrm{j}=1 / 2-x, y-1 / 2 ; 1 / 2-z ; \mathrm{k}=$ $x-1 / 2,3 / 2-y, z-1 / 2 ; 1=1 / 2-x, y+1 / 2 ; 1 / 2-z$. Top right: View of the $2 \mathrm{D}$ assembly. Bottom left: View of the packing with layers viewed edge-on. Bottom right: Simplified representation of the 2D network (yellow: uranium, red: oxygen, blue: dicarboxylate ligand, dark red: DMF). Hydrogen atoms are omitted in all views.

Figure 4. Top: View of complex 4. Displacement ellipsoids are drawn at the $40 \%$ probability level. Symmetry codes: $\mathrm{i}=3 / 2-x, y-1 / 2,3 / 2-z ; \mathrm{j}=3 / 2-x, y+1 / 2,3 / 2-z$. Middle: View of the 1D polymer. Bottom: Packing with chains viewed end-on. Hydrogen atoms are omitted in all views. 
Figure 5. Top: View of complex 5. Displacement ellipsoids are drawn at the 50\% probability level and carbon-bound hydrogen atoms are omitted. Hydrogen bonds are shown as dashed lines. Symmetry codes: $\mathrm{i}=y-x+1 / 3, y-1 / 3, z+1 / 6 ; \mathrm{j}=1-y, x-y+1, z ; \mathrm{k}=y-x, 1-x, z$; $1=y-x+2 / 3, y+1 / 3, z-1 / 6$. Bottom: View of the 3D framework with counterions, solvent molecules and hydrogen atoms omitted.

Figure 6. Top: View of complex 6. Displacement ellipsoids are drawn at the $40 \%$ probability level and carbon-bound hydrogen atoms are omitted. Hydrogen bonds are shown as dashed lines. Symmetry codes: $\mathrm{i}=x-1, y-1, z ; \mathrm{j}=-x, 2-y, 1-z ; \mathrm{k}=x+1, y+1, z$. Middle: View of the ladderlike 1D polymer. Bottom: Packing with chains viewed end-on. Hydrogen atoms are omitted in the last two views. Only one position of the disordered atoms is shown.

Figure 7. Top left: View of complex 7. Displacement ellipsoids are drawn at the $40 \%$ probability level. Symmetry codes: $\mathrm{i}=x+1 / 2, y-1 / 2, z ; \mathrm{j}=x-1 / 2, y+1 / 2, z ; \mathrm{k}=1-x, 1-y$, $1-z ; 1=1-x, 4-y, 1-z$. Top right: View of the interpenetrated 2D assembly. Bottom left: View of the packing with layers viewed edge-on. Bottom right: Nodal representations of the threefold interpenetrated 2D nets. Counterions, solvent molecules and hydrogen atoms are omitted in all views.

Figure 8. Top left: View of complex 8. Displacement ellipsoids are drawn at the $40 \%$ probability level. Symmetry codes: $\mathrm{i}=1 / 2-x, y-1 / 2,-z-1 / 2 ; \mathrm{j}=1 / 2-x, y+1 / 2,-z-1 / 2$; $\mathrm{k}$ $=1-x,-y, 1-z ; 1=-x, 1-y, 1-z$. Top right: View of the interpenetrated 3D framework. Bottom left: View showing the helical subunit formed by the $c-1,4-$ chdc $^{2-}$ ligand alone (parallel to $\left.\left[\begin{array}{lll}0 & 1 & 0\end{array}\right]\right)$ in the upper part, connected to a series of chains (viewed end-on) formed by the $t$ - 
1,4-chdc ${ }^{2-}$ ligand alone (parallel to [ $\left.\begin{array}{lll}1 & 1 & 0\end{array}\right]$ ) in the lower part. Bottom right: Nodal representation of the threefold interpenetrated 3D nets. Counterions, solvent molecules and hydrogen atoms are omitted in all views, and only one position of the disordered atoms is shown.

Figure 9. Top: View of complex 9. Displacement ellipsoids are drawn at the $40 \%$ probability level. Symmetry codes: $\mathrm{i}=z+1 / 2,3 / 2-x, 1-y ; \mathrm{j}=3 / 2-y, 1-z, x-1 / 2 ; \mathrm{k}=y, z, x ; 1=z, x$, $y$. Middle: View of the 3D framework. Solvent molecules and hydrogen atoms are omitted in both views, and counterions in the last view. Bottom: Nodal representation of the $3 \mathrm{D}$ framework (yellow: uranium, blue: dicarboxylate ligand); slightly rotated from the orientation of the previous view.

Figure 10. View of complex 10. Displacement ellipsoids are drawn at the $30 \%$ probability level. Solvent molecules and hydrogen atoms are omitted. Symmetry codes: $\mathrm{i}=3 / 2-z, 1-x$, $y+1 / 2 ; \mathrm{j}=1-y, z-1 / 2,3 / 2-x ; \mathrm{k}=z-1 / 2,1 / 2-x, 1-y ; 1=1 / 2-y, 1-z, x+1 / 2$. The $3 \mathrm{D}$ framework is similar to that in the isomorphous complex 9.

Figure 11. Top: View of complex 11. Displacement ellipsoids are drawn at the 50\% probability level. Symmetry code: $\mathrm{i}=1-x, 1-y, 2-z$. Middle: View of the packing with nickel atoms shown as blue spheres. Solvent molecules and hydrogen atoms are omitted in both views. Bottom: View of the Hirshfeld surface of the anionic complex showing the hydrogen bonding interactions with cations and solvent molecules.

Figure 12. Top left: View of complex 12. Displacement ellipsoids are drawn at the 50\% probability level. Symmetry codes: $\mathrm{i}=x,-y, z+1 / 2, \mathrm{j}=x-1,1-y, z+1 / 2 ; \mathrm{k}=x,-y, z-1 / 2$; $1=x+1,1-y, z-1 / 2$. Top right: View of the interpenetrated 3D framework with copper atoms 
shown as blue spheres. Bottom: Two nodal views of the twofold interpenetrated 3D nets. Solvent molecules and hydrogen atoms are omitted in all views.

Figure 13. Top left: View of complex 13. Displacement ellipsoids are drawn at the $40 \%$ probability level. Symmetry codes: $\mathrm{i}=x+1 / 2,1 / 2-y, z+1 / 2 ; \mathrm{j}=1-x,-y, 1-z ; \mathrm{k}=x-1 / 2$, $1 / 2-y, z-1 / 2$. Top right: View of the $2 \mathrm{D}$ assembly with counterions omitted. Bottom left: View of the packing with layers viewed edge-on and zinc atoms shown as green spheres. Bottom right: Simplified representations of the 2D assembly (yellow: uranium, red: oxygen, blue: dicarboxylate ligand). Solvent molecules and hydrogen atoms are omitted in all views.

Figure 14. Top: View of complex 14. Displacement ellipsoids are drawn at the 50\% probability level. Symmetry codes: $\mathrm{i}=x+1, y, z ; \mathrm{j}=1-x, y-1 / 2 ; 1 / 2-z ; \mathrm{k}=-x, y-1 / 2 ; 1 / 2-z ; 1=1-$ $x, y+1 / 2 ; 1 / 2-z ; \mathrm{m}=x-1, y, z ; \mathrm{n}=-x, y+1 / 2 ; 1 / 2-z ; \mathrm{o}=2-x, 1-y, 1-z ; \mathrm{p}=2-x,-y, 1$ $-z ; \mathrm{q}=x+1,1 / 2-y ; z+1 / 2$. Middle: View of the 3D framework with lead atoms shown as green spheres. Bottom: Simplified representation of the framework (yellow: uranium, green: lead, red: oxygen, blue: dicarboxylate ligand, dark red: bipy). Hydrogen atoms are omitted in all views.

Figure 15. Emission spectra of complexes 1, 2, 5, 8, 10, 11 and 13, recorded in the solid state with an excitation wavelength of $420 \mathrm{~nm}$.

Figure 16. Distribution of the positions of the four most intense emission peaks in a series of uranyl carboxylate complexes, with the equatorial environments $\mathrm{O}_{6}$ (blue), $\mathrm{O}_{4} \mathrm{~N}_{2}$ (green), $\mathrm{O}_{5}$ (red), and $\mathrm{O}_{4}$ (orange). 
Figure 1
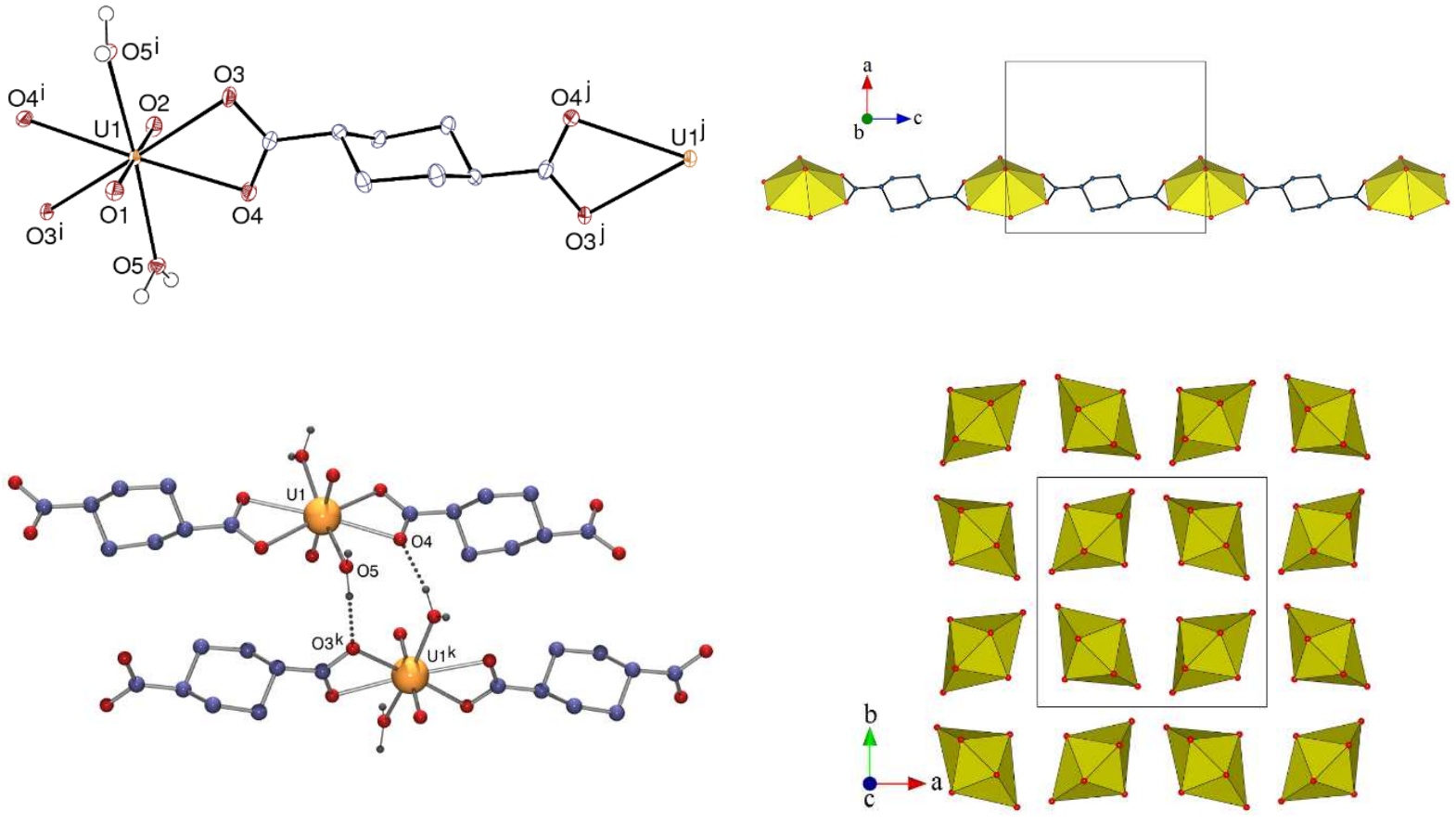
Figure 2
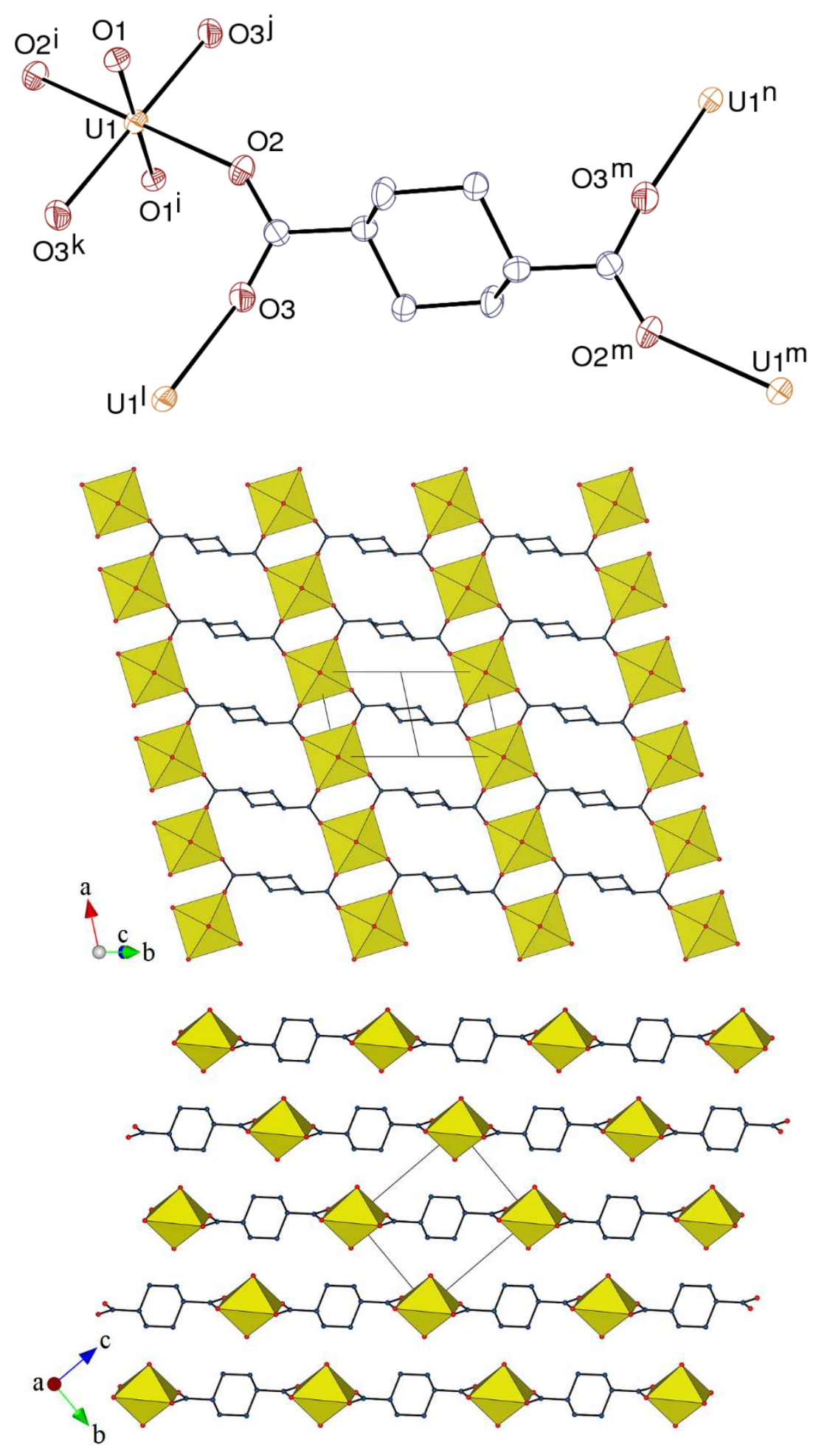
Figure 3
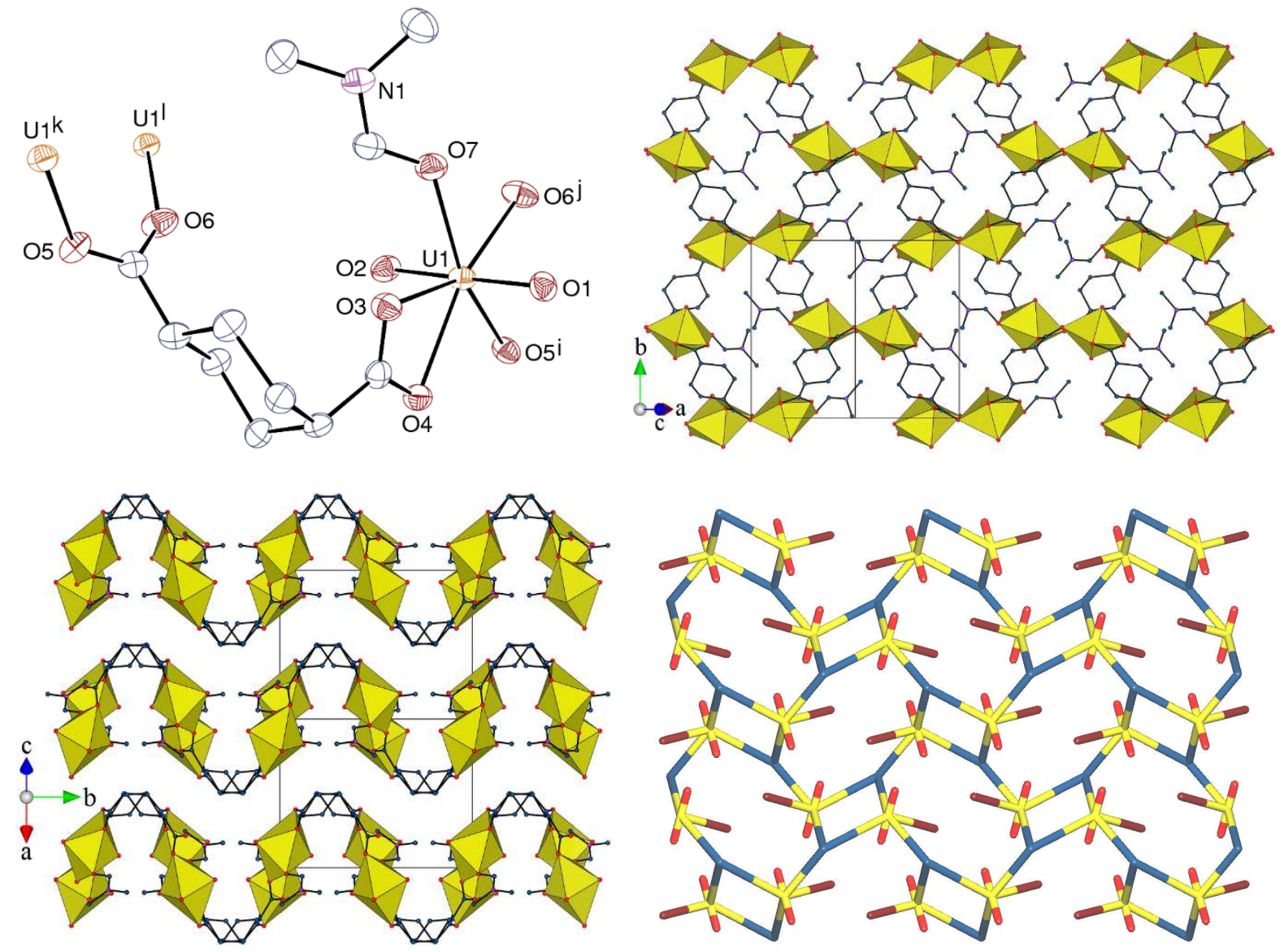
Figure 4
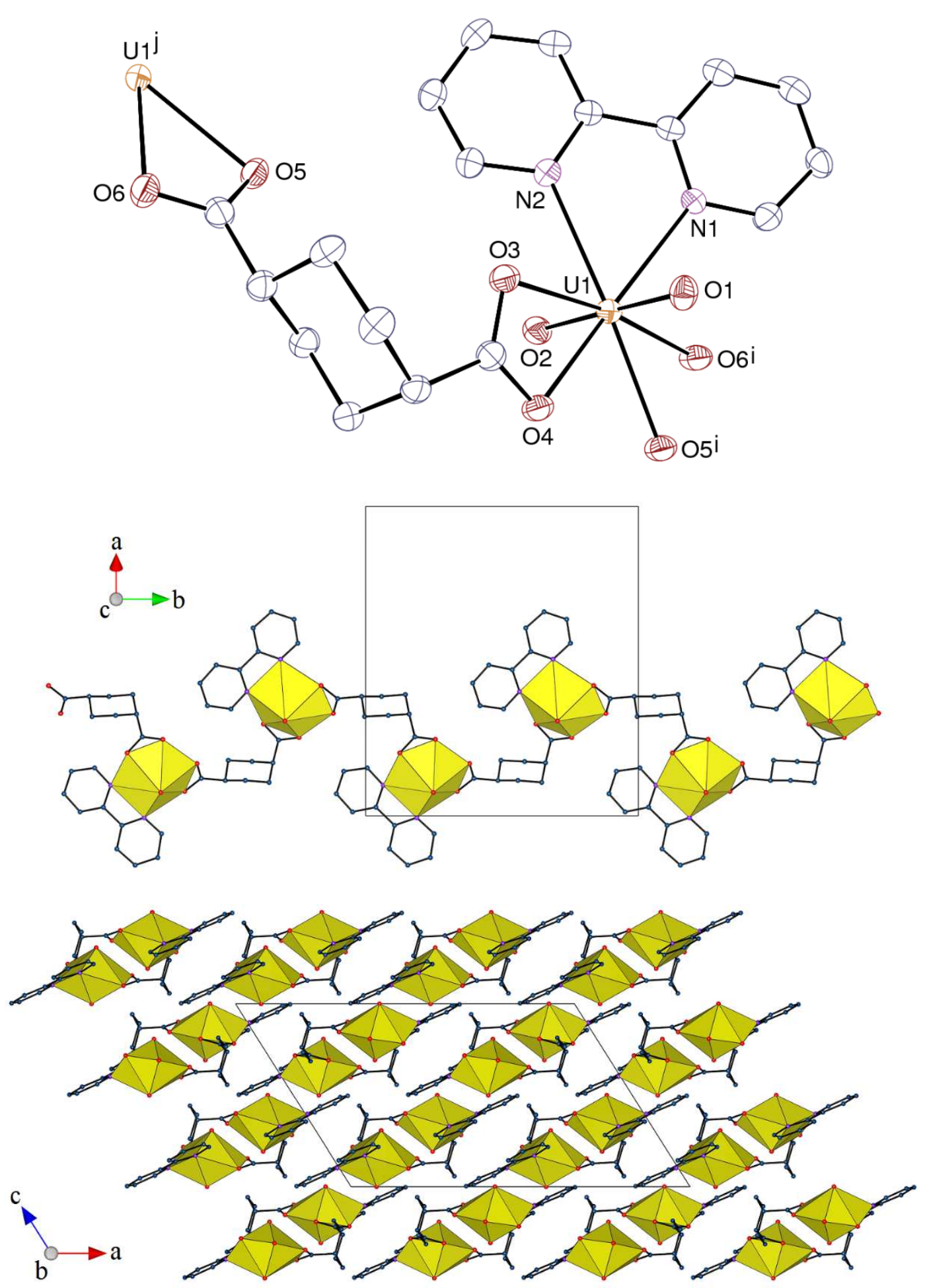
Figure 5
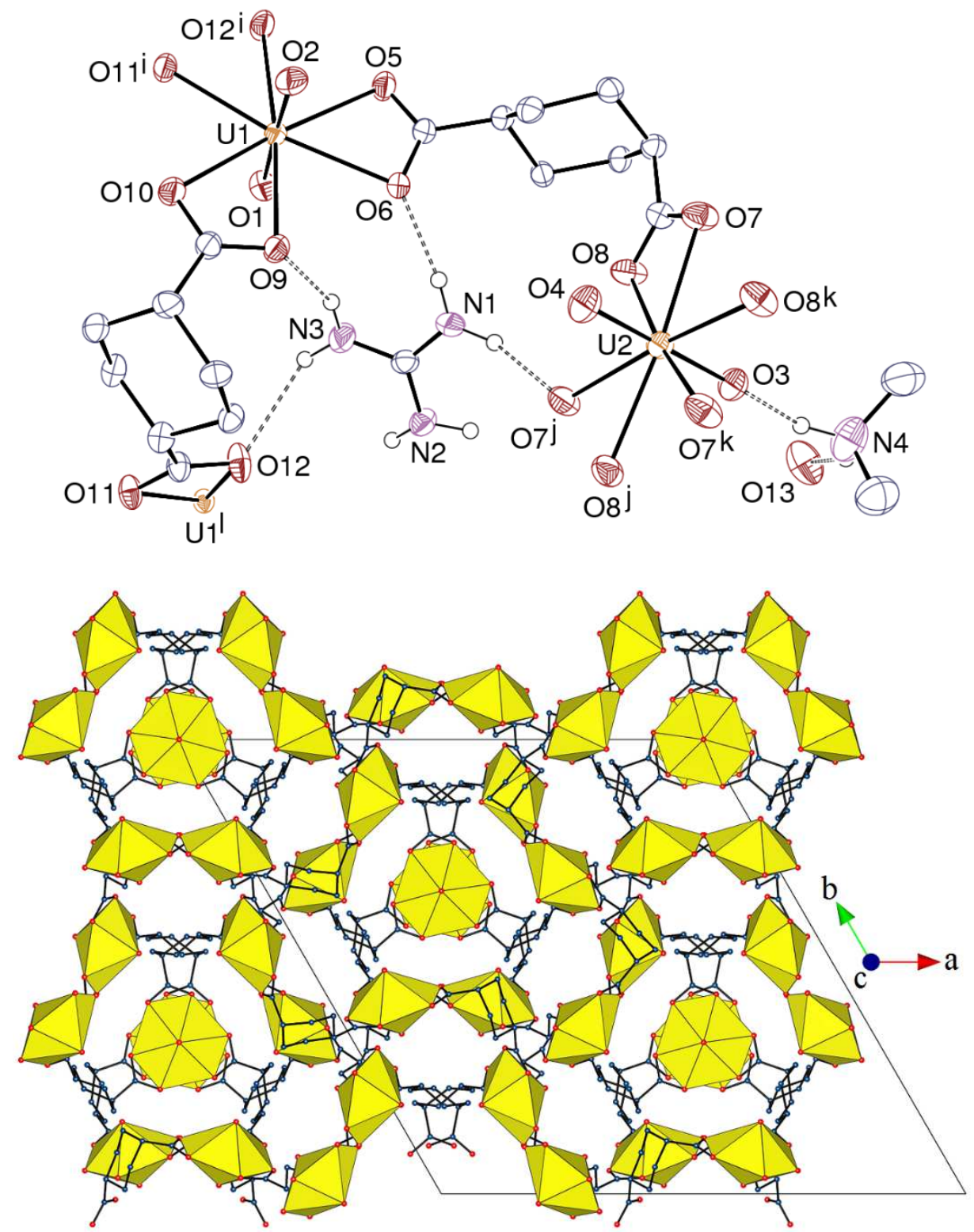
Figure 6
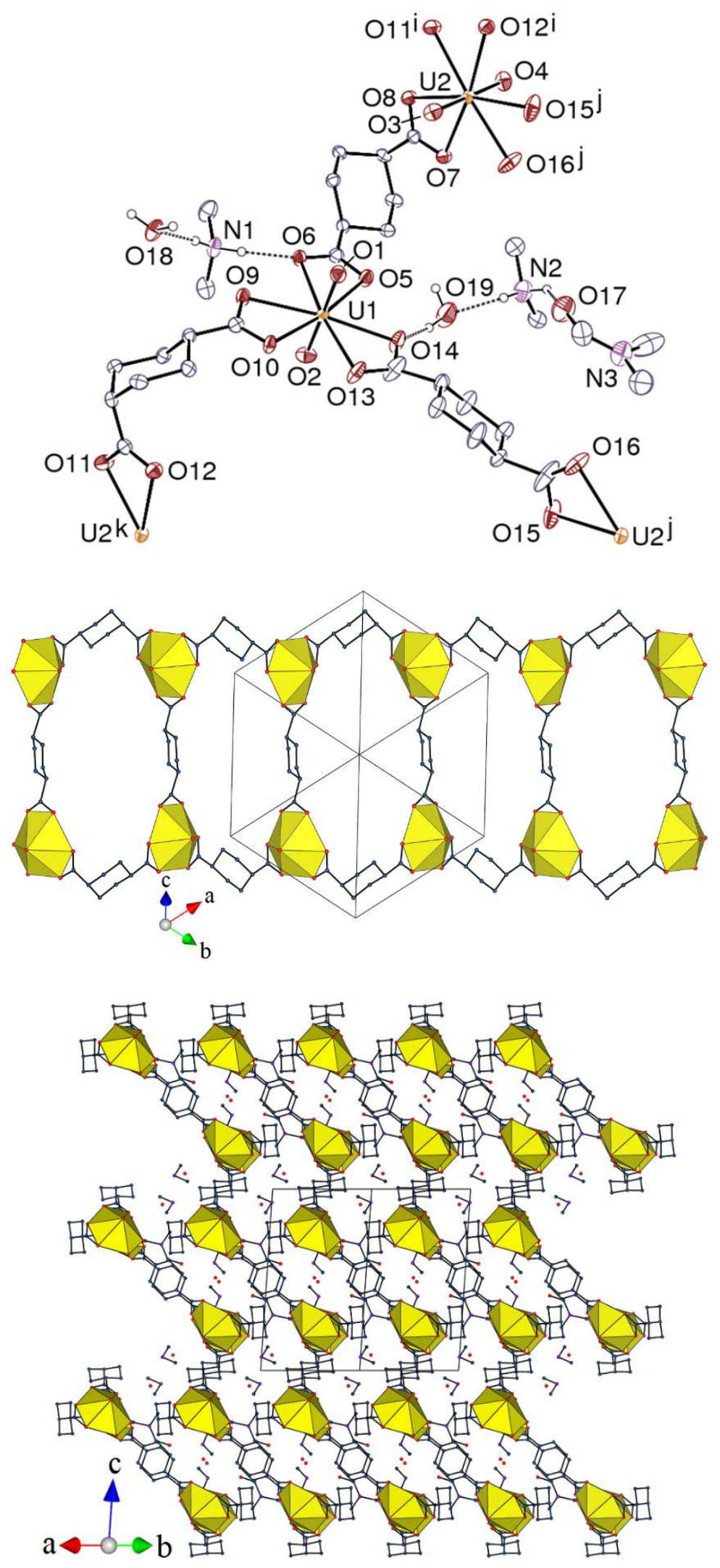
Figure 7
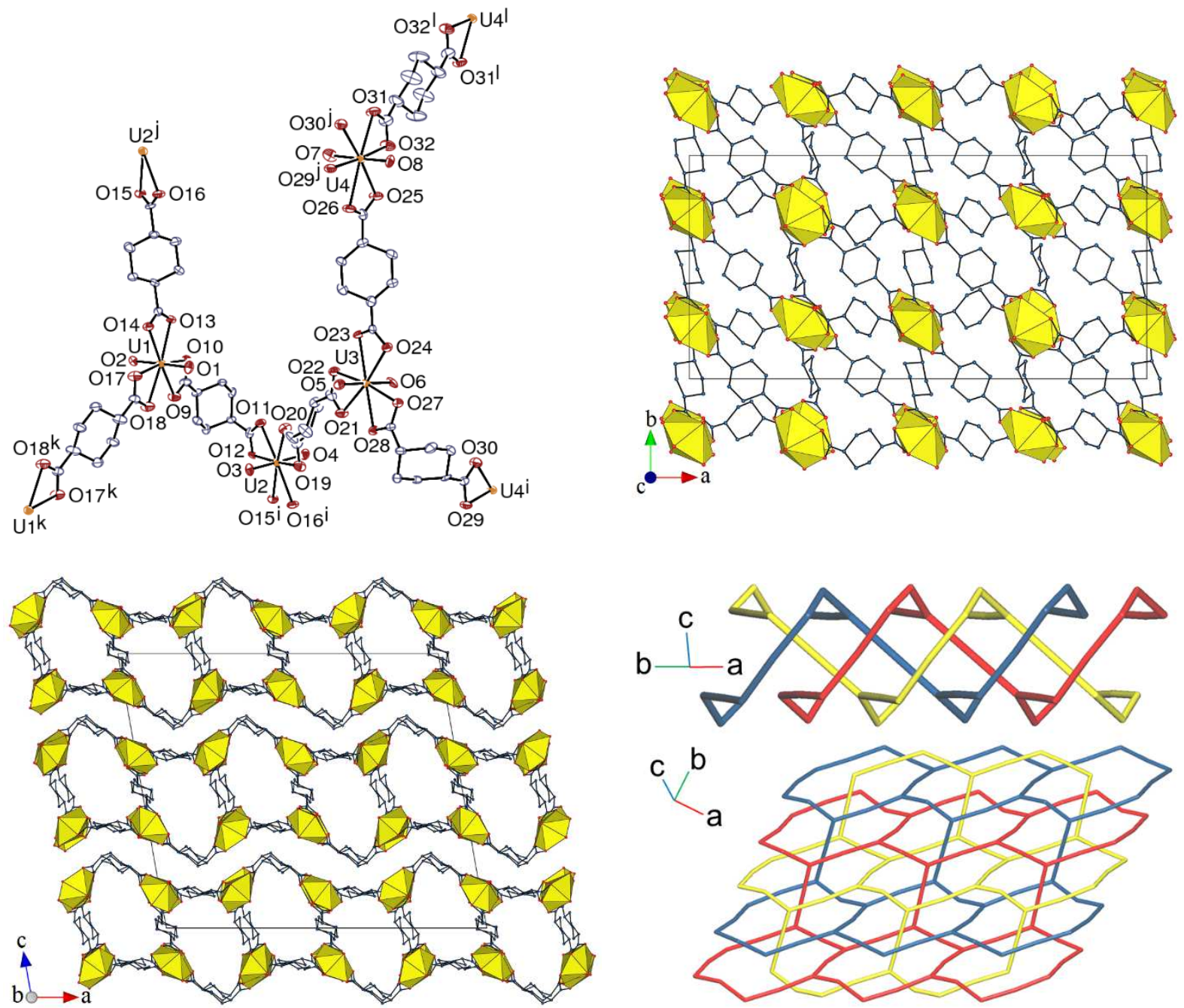
Figure 8
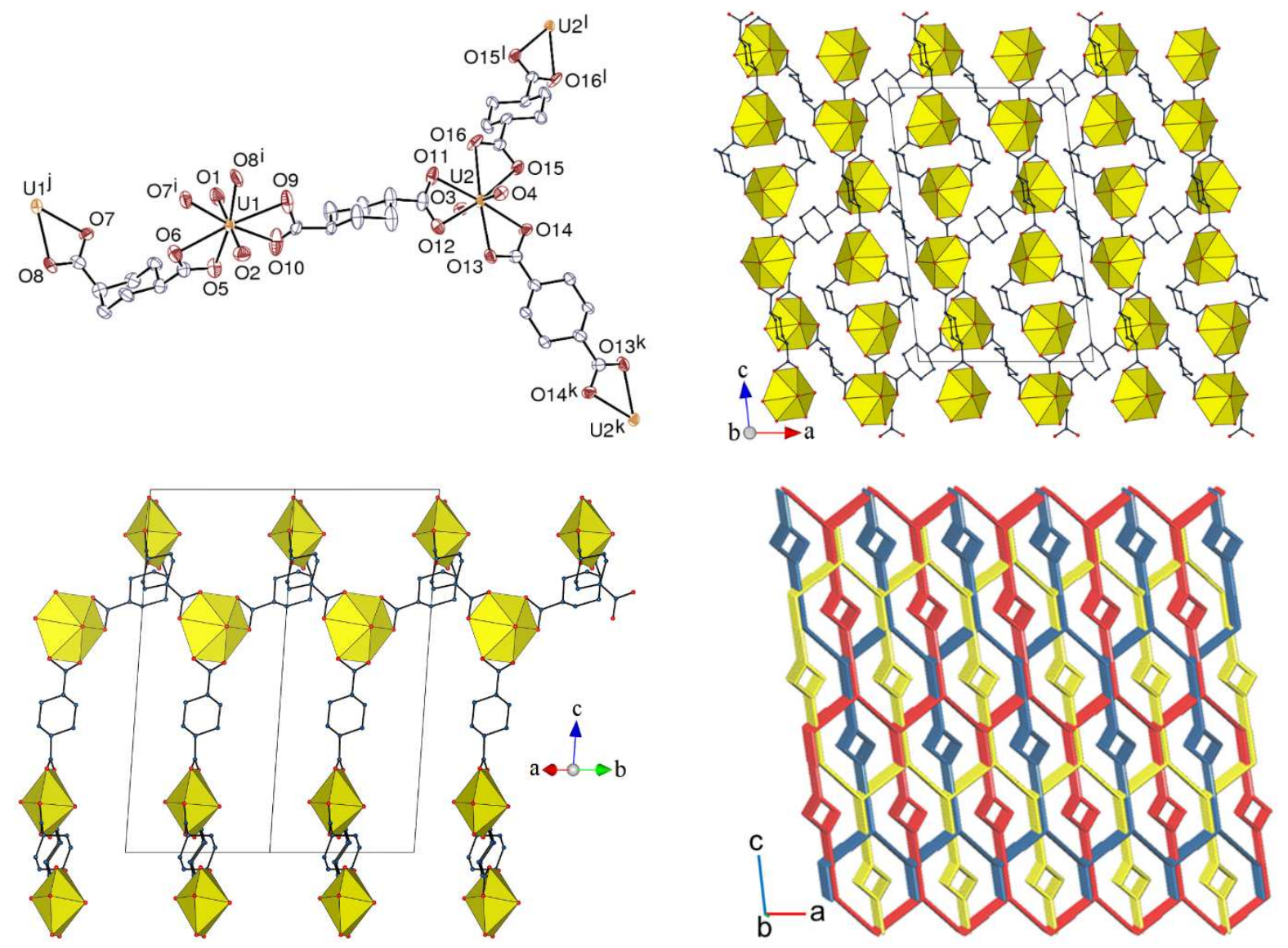
Figure 9
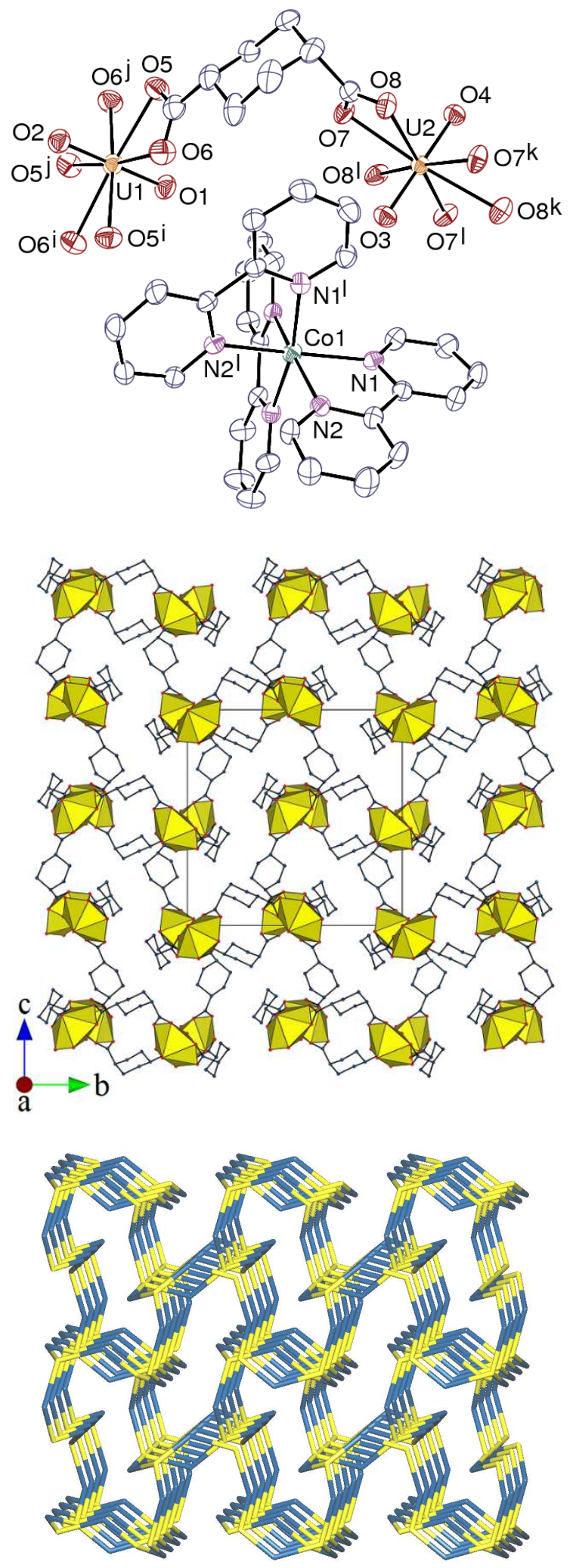
Figure 10

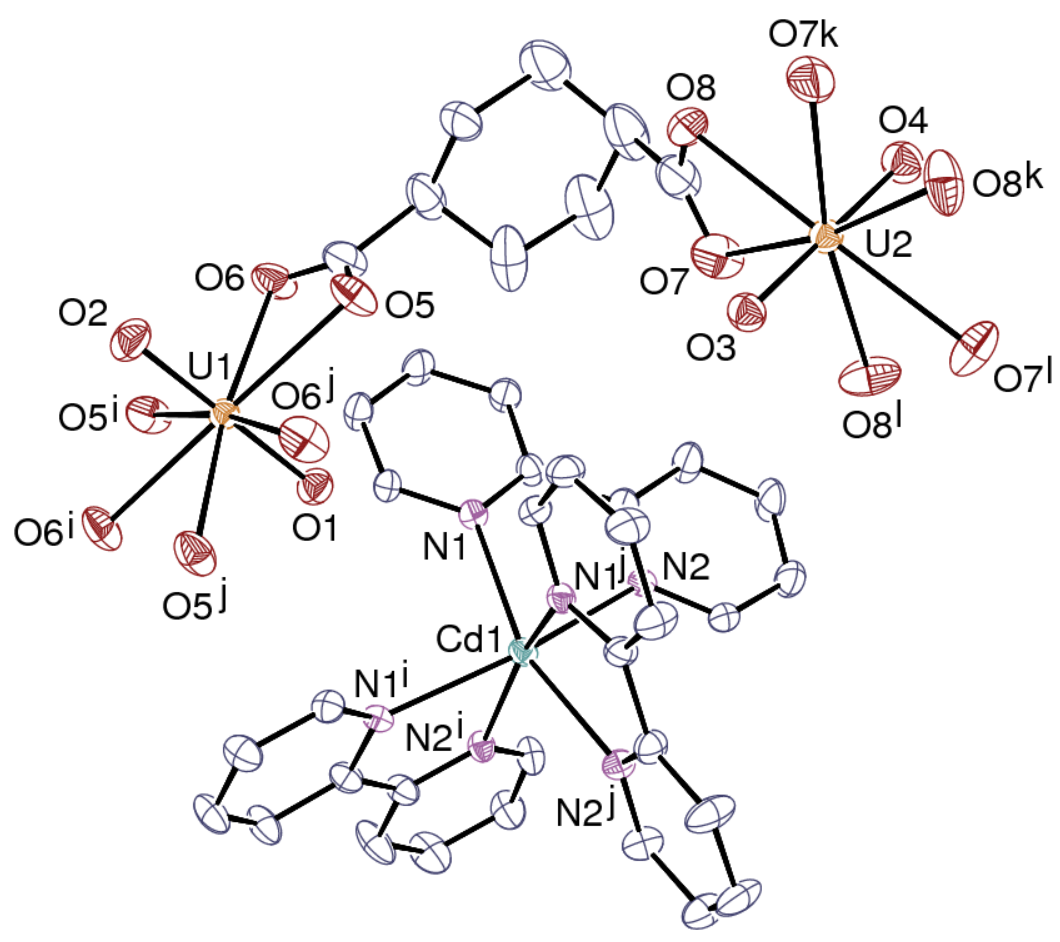


Figure 11
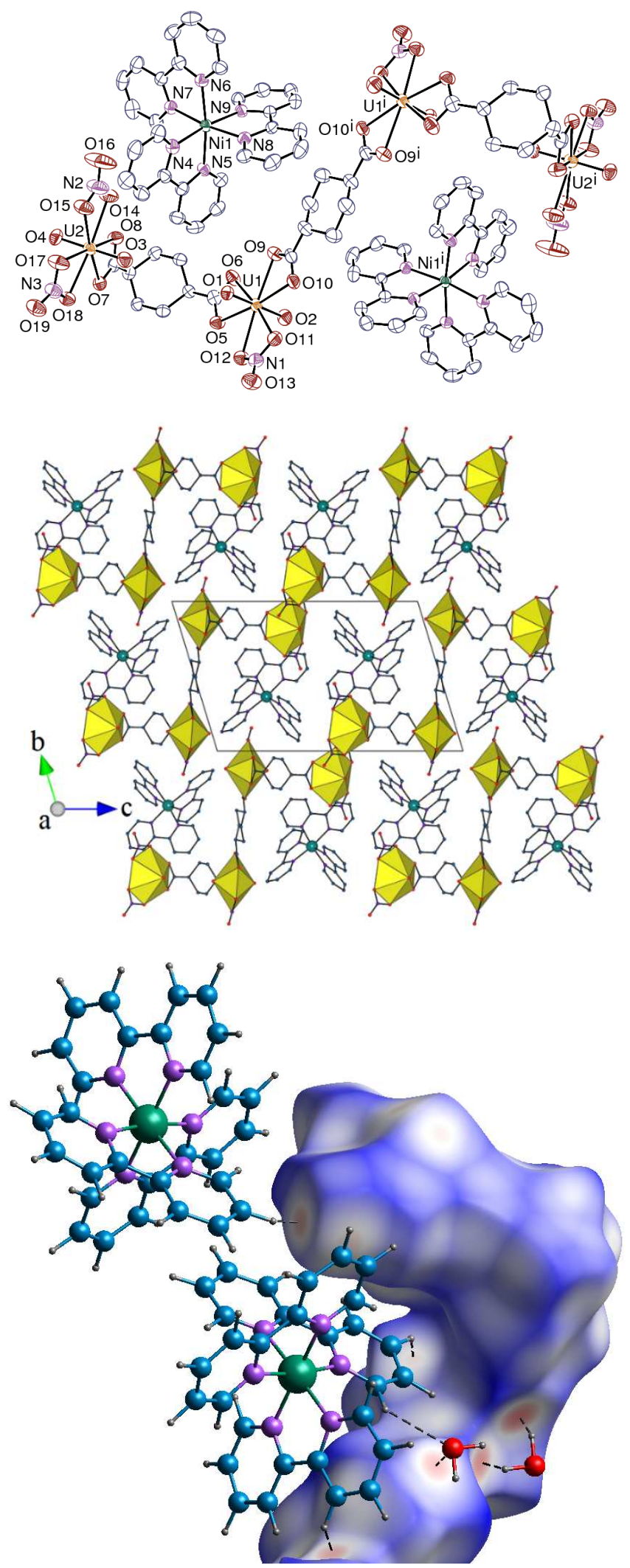
Figure 12
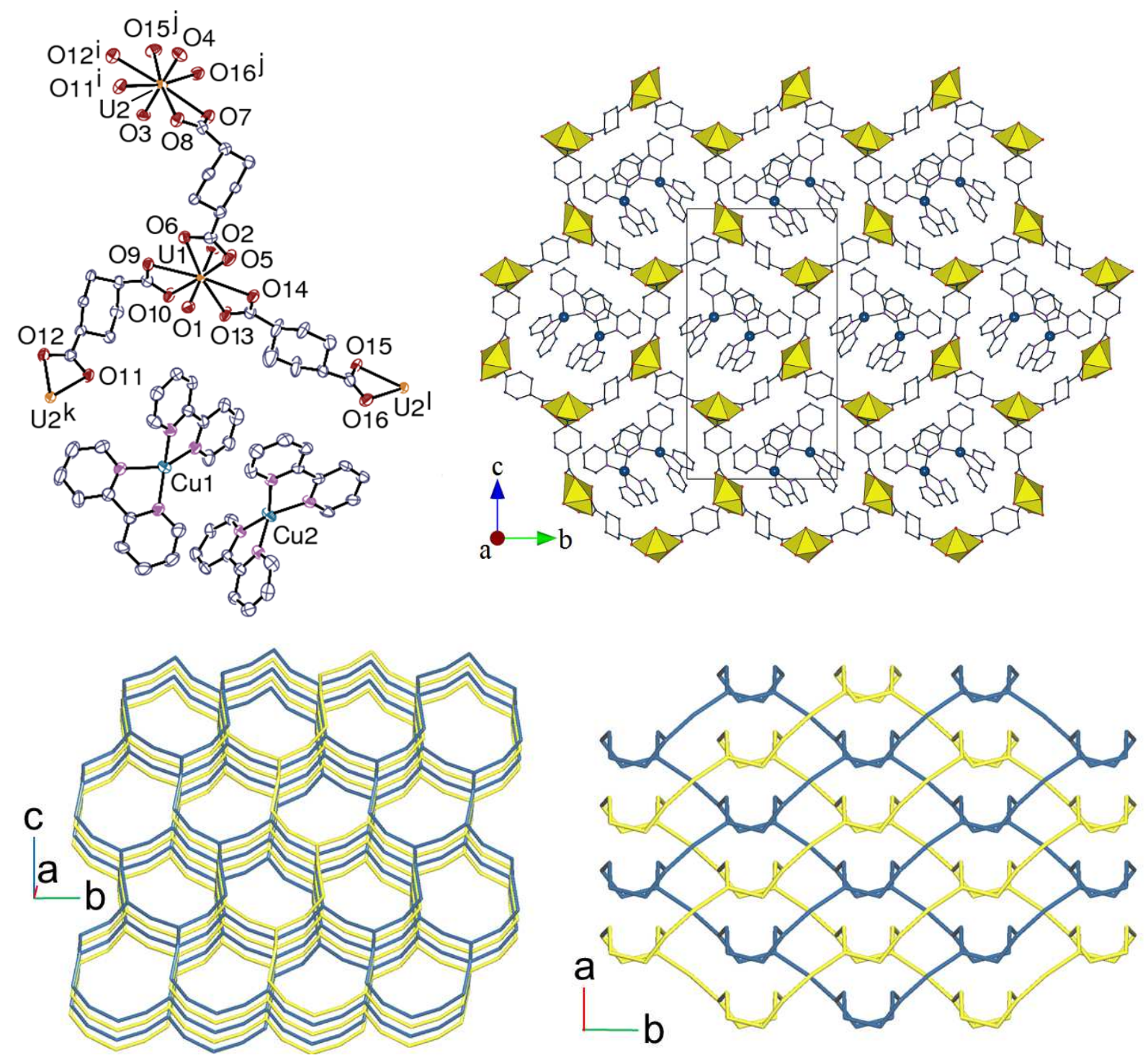
Figure 13
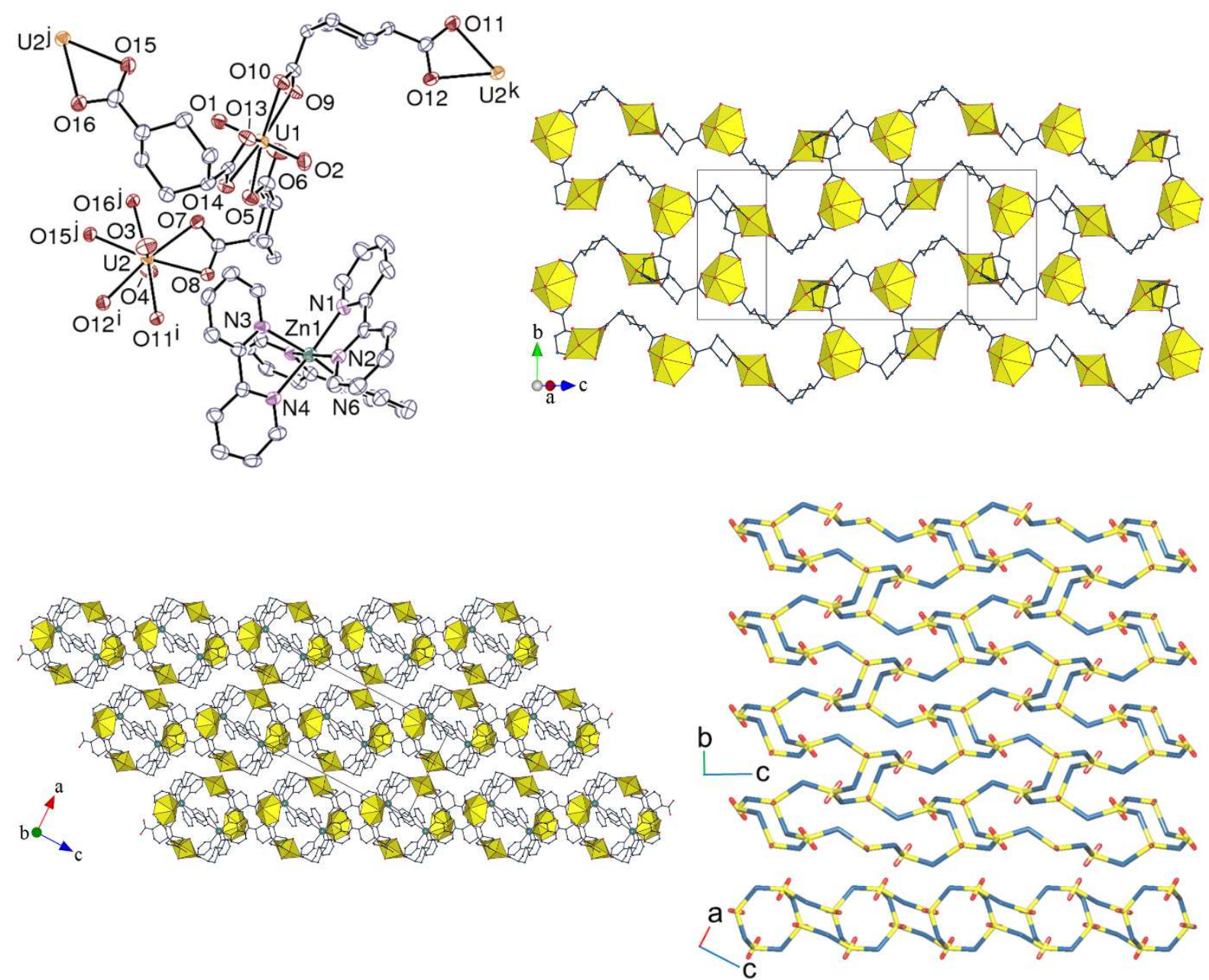
Figure 14
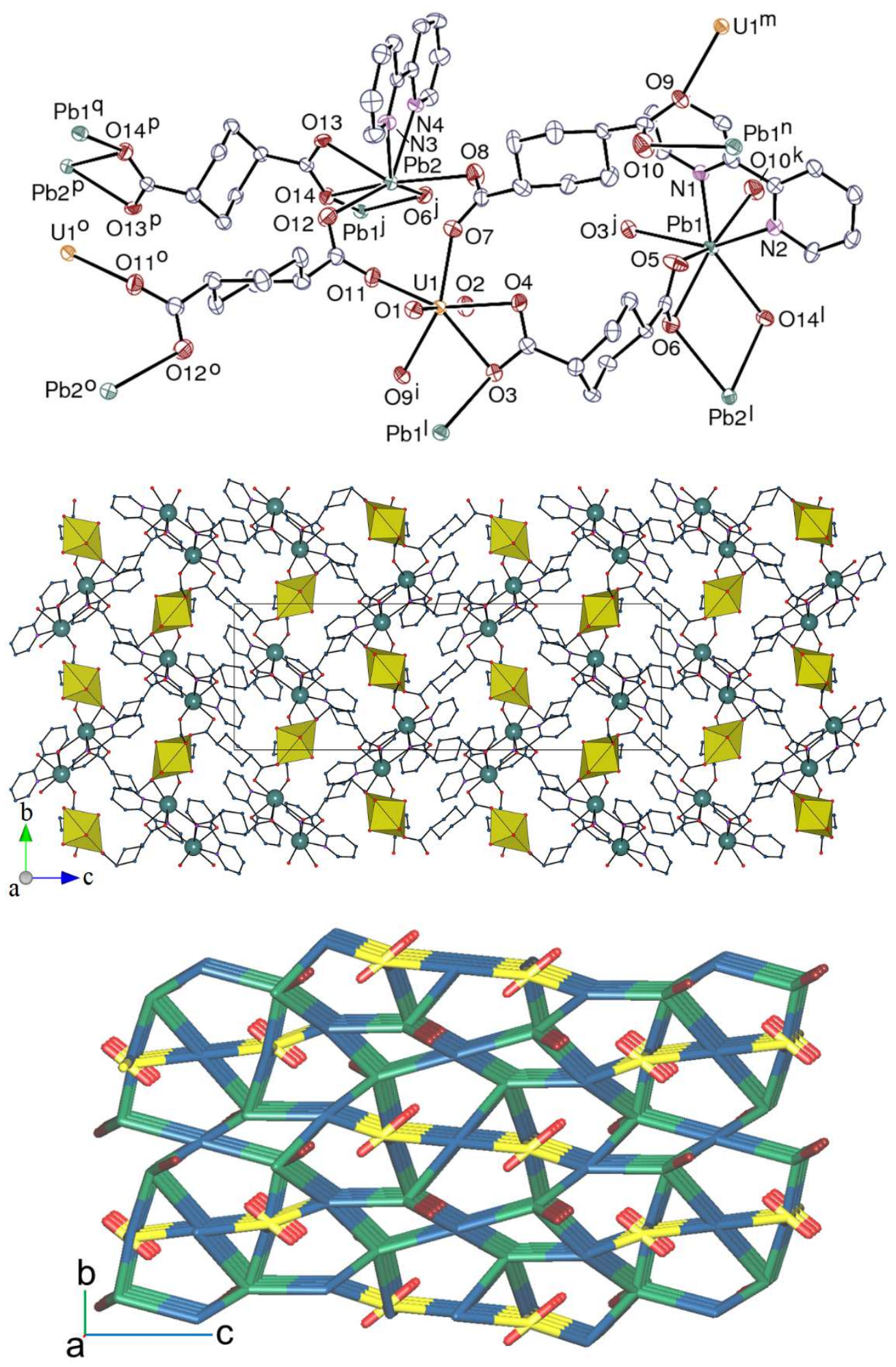
Figure 15

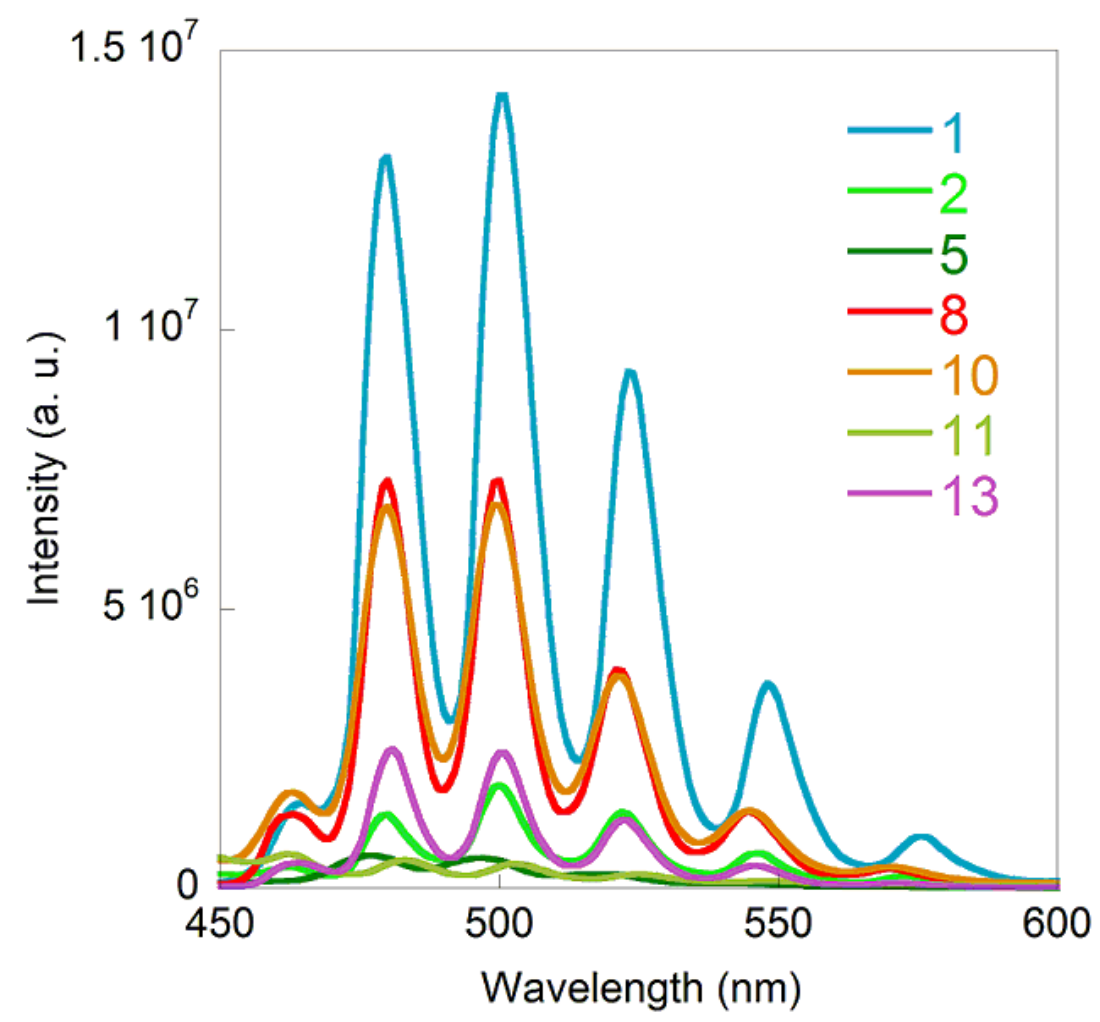

Figure 16

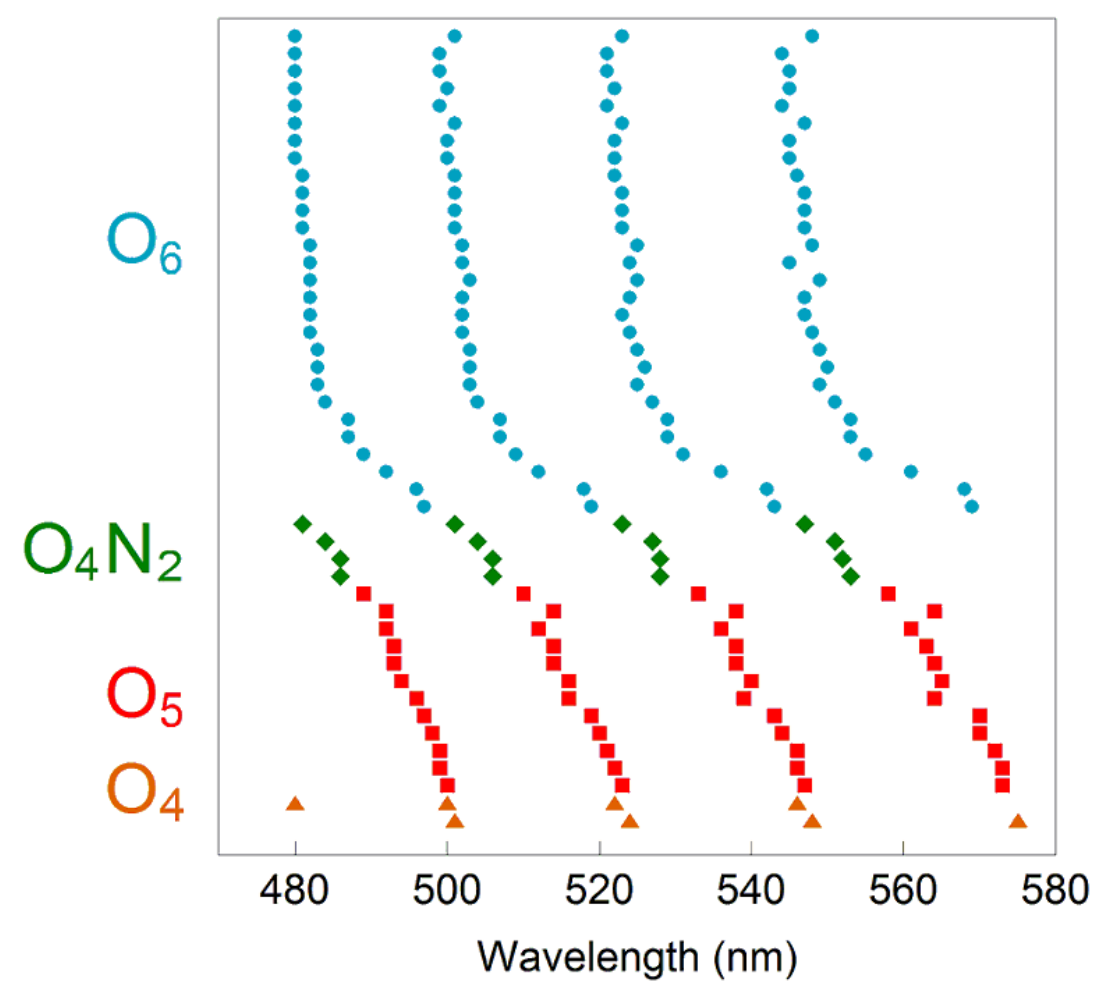




\section{Structural Consequences of 1,4-Cyclohexanedicarboxylate cis/trans Isomerism in Uranyl Ion Complexes: from Molecular Species to 2D and 3D Entangled Nets}

Pierre Thuéry and Jack Harrowfield

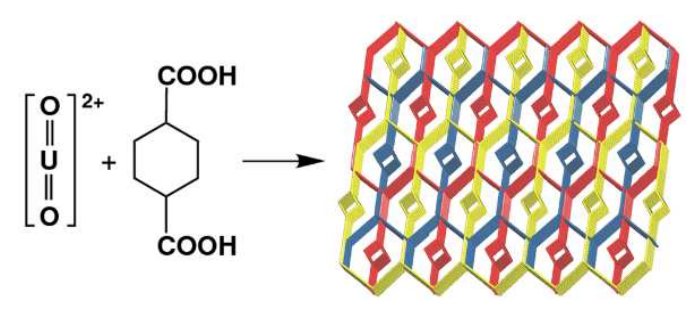

The crystal structures of 14 uranyl complexes containing either the trans or cis isomers of 1,4cyclohexanedicarboxylate, or a mixture of both, have been determined, showing a strong dependence on the experimental conditions, and particularly on the organic or metallic counterions present. The complexes formed have dimensionalities in the whole 0-3 range, and three novel examples of interpenetrated two- and three-dimensional networks are reported. Uranyl emission spectra fit with the general trend observed with other polycarboxylate ligands. 